Policy transmission in Indian money markets: The role of liquidity

Ashima Goyal and Deepak Kumar Agarwal

Indira Gandhi Institute of Development Research, Mumbai August 2019 


\title{
Policy transmission in Indian money markets: The role of liquidity
}

\author{
Ashima Goyal and Deepak Kumar Agarwal
}

Email(corresponding author): ashima@igidr.ac.in

\begin{abstract}
We derive testable implications for transmission from Indian policy rate and liquidity provision to market rates as well as the interaction between rate and liquidity channels, from an analysis of operating procedures and estimate using event window regressions. The interest rate transmission channel is dominant, but the quantity channel has an indirect impact on the size of interest rate pass through. Short run government securities (G-Secs) yields are most responsive to changes in policy rates. Asymmetry or faster and more adjustment during tightening is found only for G-Secs rates. Liquidity changes matter for short term rates and durable liquidity for longer term government securities. Collateralized short-term market rates respond to the direction of change in Repo when liquidity changes are aligned. These or short-run G-Secs should form the operating target. Liquidity variables increase the size of the G-Secs Repo coefficients, suggesting aligned liquidity increases the impact of a change in the Repo Rate. The results highlight an important asymmetry in monetary transmission for emerging markets in the special role of liquidity in comparison to rates. Implications follow for policy.
\end{abstract}

Keywords: Money markets; transmission; Repo Rate; liquidity

JEL Code: E51; E58; E42

\section{Acknowledgements:}

We thank Dr. Kanagasabapathy, Dr. B. K. Bhoi and anonymous referees for useful comments and Reshma Aguiar for secretarial assistance. This is a substantially revised version of IGIDR working paper no. WP-2017-017. 


\section{Policy transmission in Indian money markets: The role of liquidity}

\section{Introduction}

The Reserve Bank of India (RBI) moved towards using the Repo rate instead of monetary aggregates as the instrument of monetary policy after 2002. This followed the liberalizing reform in the nineties that allowed interest rates to be market determined, and by reducing fiscal dominance that implied automatic monetization of the fiscal deficit, gave the RBI control over its balance sheet. A Liquidity Adjustment Facility (LAF) was introduced to provide short-term liquidity (STL), largely overnight through repurchase transactions (Repos), but going up to 28 days through term Repos. This was meant to adjust for any imbalance between banks' demand for long-term liquidity (LTL) and its supply. Collateralized overnight liquidity was supplied on banks' demand at the Repo rate. Excess overnight liquidity with banks was absorbed at the Reverse Repo rate. These rates defined a LAF band, within which the Call Money Rate (CMR), the overnight uncollateralized interbank borrowing rate, which was the operating target for policy, was to stay. Only banks had access to LAF borrowing and they were expected to meet the liquidity needs of the rest of the economy.

LTL affects the RBI's balance sheet. Open Market Operations (OMOs), and foreign exchange (FX) market intervention (involving purchase and sale of government securities (G-Secs)), Cash Reserve Requirement (CRR the percentage of their deposits commercial banks have to keep as cash reserves with the RBI) and Market Stabilisation Scheme (MSS special G-secs created for sterilization) affect long-term durable liquidity, which is also the reserve money. The RBI aims to accommodate LTL to changes in money demand in line with nominal income growth. There are many definitions of liquidity, but in this paper we are concerned with transmission of policy rates through markets using the LAF system and role, if any, of STL and LTL.

Considerable development of the money market supported the LAF (Table 1). Active money markets fulfil short term borrowing needs and also help maintain liquidity, so that RBI intervention should be required only at the margin. New instruments such as Certificates of Deposit (CD), Commercial Papers (CP) and Collateralized Borrowing and Lending Obligations (CBLO) contributed to the money market demand and supply equilibrium, making short-term funds available for those willing to borrow from those willing to lend. Government securities markets also showed significant growth. For most instruments, however, rates of growth were higher in the first half of our period of analysis (2002-18), reflecting either a lower base or higher economic activity in that period. 
Table 1 shows, however, the call money market turnover was actually smaller at the end of the period compared to the beginning. Borrowing from the RBI through Repos was much larger.

\begin{tabular}{|c|c|c|c|c|c|c|c|}
\hline \multirow[b]{2}{*}{$\begin{array}{l}\text { S. } \\
\text { No. }\end{array}$} & \multirow[b]{2}{*}{ Nomenclature } & \multicolumn{3}{|c|}{ Volume (Rs. Crores) } & \multicolumn{3}{|c|}{ Percentages } \\
\hline & & $2002-03(X)$ & 2009-10 (Y) & 2017-18 (Z) & $\begin{array}{l}\text { Compound } \\
\text { Annual } \\
\text { Growth } \\
\text { (X to Y) }\end{array}$ & $\begin{array}{l}\text { Compound } \\
\text { Annual } \\
\text { Growth } \\
(Y \text { to } Z)\end{array}$ & $\begin{array}{l}\text { Compound } \\
\text { Annual } \\
\text { Growth } \\
(\mathrm{X} \text { to } \mathrm{Z}) \\
\end{array}$ \\
\hline 1 & Call/Notice/Term Money ${ }^{*}$ & 4517510.04 & 2530236.4 & 3869255.13 & -7.95 & 5.45 & -1.03 \\
\hline 2 & CDs & 32289 & 6395074 & 3664559.08 & 112.87 & -6.72 & 37.09 \\
\hline 3 & CPs & 199200 & 1977473 & 10220459.83 & 38.8 & 22.79 & 30.02 \\
\hline 4 & CBLO & $976789^{a}$ & 14859364.1 & 25740213.8 & 72.36 & 7.11 & 28.62 \\
\hline 5 & Market Repo & $1560510^{\mathrm{a}}$ & 6072828.37 & 10834094.11 & 31.23 & 7.50 & 16.07 \\
\hline 6 & Central Government Securities & 1293383.43 & 2558041.09 & 9744575.38 & 10.23 & 18.20 & 14.41 \\
\hline 7 & Treasury Bills & 75515.36 & 387101.11 & 858461.96 & 26.3 & 10.47 & 17.59 \\
\hline 8 & $\begin{array}{l}\text { Total Government Securities } \\
(6+7)\end{array}$ & 1368898.79 & 2945142.2 & 10603037.34 & 11.57 & 17.37 & 14.62 \\
\hline
\end{tabular}

Our objective is to explore the transmission from the Repo rate to market rates in this period of change and if it is affected by RBI liquidity operations. The Indian case is particularly interesting as markets had to shift from quantity to rate signals after 2011 when, following the recommendations of RBI (2011), it was decided to keep LTL in deficit and STL in the injection mode following the practice in many advanced countries (AEs). This meant, even during periods of monetary loosening, banks would have to borrow in the inter-bank market or over-night from the RBI to maintain their required reserves. Quantity (liquidity) signals would not be aligned with price (rate) signals. Liquidity would be tight when the rate was falling. RBI's position was that transmission would work better through liquidity constrained banks with STL in deficit mode. But does evidence supports this for an emerging market (EM) like India? Is there an asymmetry between AEs and EMs? Indian banks were not comfortable with having to borrow short-term while lending long-term and asked for rate and quantity signals to be aligned.

While there is a large literature on Indian monetary transmission it tends to focus on transmission from rates to inflation and output (Aleem 2010, Bhoi et al. 2017, Mishra and Mishra 2012) using Vector Auto Regression (VAR) based estimation and finds some evidence for this. But the transmission from policy to market rates is hardly studied. There are international studies of the money market, liquidity provision and transmission especially after the global financial crisis created disturbances in money markets (Friexas, Martin and Skeie, 2011), but they are specific to US money markets (Carpenter and Demiralp, 2006; Demiralp and Farley, 2005). Little is known 
about the process of transition as money markets develop in EMs. Qiao and Liu (2017) is an early study for China, whose event window based methodology we follow.

In line with our objective, event windows centred on Repo rate change dates enable us to examine the speed and extent of pass through, and the role that short and long term liquidity plays in enabling it. We assess if pass through is better when liquidity is in sync with the Repo rate change, or when it is kept in deficit. We also search for symmetry of market responses. That is, is transmission more for a rise or for a fall in the Repo rate; is it more when liquidity is being reduced or increased. There are asymmetries in transmission-banks tend to be faster to raise loan rates when policy rates rise, but are tardy in cutting rates when policy loosens. In market also, large borrowings may give rates an upward bias.

A simple theoretical framework for the LAF predicts that an operating procedure that does not respond to shocks to liquidity demand will reduce turnover in the call money market as observed in the Indian case. Liquidity provision and the share of LTL matters, therefore. Empirical results show the interest rate transmission channel to be dominant, but the quantity channel does have an indirect impact on the size of interest rate pass through. Short run G-Secs yields are most responsive to changes in policy rates. Asymmetry or faster and more adjustment during tightening is found only for G-Secs rates. Liquidity changes matter for short term rates and total or durable liquidity for longer term G-Secs. Collateralized short-term market rates respond to the direction of change in Repo when liquidity changes are aligned, that is liquidity is in deficit only when policy tightens. Liquidity variables increase the size of Repo coefficients in G-Secs regressions, suggesting when liquidity is aligned with it the impact of a change in the Repo rate increases. The results imply there is an important asymmetry in monetary transmission for EMs in the special role for liquidity despite having an interest rate target. One reason is they are less able to forecast and respond to larger exogenous shocks to liquidity demand so that the share of short-term liquidity becomes too large when it is kept in deficit. Implications follow for policy.

The remaining paper is structured as follows: Section 2 presents an analytical framework that helps to understand aspects of the Indian experience with the LAF. Section 3 gives a brief literature review and section 4 outlines the data and presents it in stylized facts and graphs showing composition and trends of short term and long term liquidity corresponding to phases of policy and movements of market rates corresponding to policy rates. Section 5 uses regression analysis to examine transmission in market rates. Section 6 concludes the paper, also providing implications for policy. 


\section{Analytical Framework}

Equation 1 shows that total liquidity supply at time $t$ is the sum of short term (LAF) liquidity and long term (durable) liquidity.

$$
T L_{t}^{S}=S T L_{t}^{S}+L T L_{t}^{S}
$$

Demand for total liquidity depends negatively on cost and positively on factors affecting money demand. So in equation 2 it is negatively related to the CMR, which measures borrowing cost in money markets, and to exogenous shocks $\epsilon_{t}^{d}$. Since we want to model the money market the transaction demand for cash as a function of income, foreign inflows or outflows, government spending etc that affect the demand for liquidity are all included in the exogenous shocks.

$$
T L_{t}^{d}=-a C M R_{t}+\epsilon_{t}^{d}
$$

The supply of STL depends on the spread between the CMR and the policy rate, which determines money market borrowing (equation 3). If the CMR rises to or above the Repo, the borrowing is from the RBI. There is also a borrowing shock $\epsilon_{t}^{s}$. LTL is determined by the policy response in allowing expansion of LTL to accommodate each of these shocks as well as the monetary policy shock proper $\epsilon_{t}^{m}$. The money market equilibrium 5 requires the supply of short and long term liquidity to equal the demand for total liquidity ${ }^{1}$.

$$
\begin{aligned}
& S T L_{t}^{S}=b\left(C M R_{t}-\operatorname{Repo}_{t}\right)+\epsilon_{t}^{S} \\
& L T L_{t}^{S}=\Psi^{d} \epsilon_{t}^{d}+\Psi^{s} \epsilon_{t}^{S}+\epsilon_{t}^{m} \\
& T L^{d}=S T L^{S}+L T L^{S}
\end{aligned}
$$

The policy responses under the Indian LAF regime implemented during the post 2014 inflation targeting (IT) period implied $\Psi^{d}$ and $\Psi^{s}$ were close to zero. Since in a LAF liquidity supply adjusts to demand absence of adjustment of LTL meant the entire shocks to liquidity demand had to be met through variation in STL.

Figure 1 shows the liquidity supply curve under LAF, with two horizontal stretches. The first indicates absorption of excess liquidity by the RBI at the Reverse Repo rate RR. When liquidity reaches the target deficit of 0.5 NDTL the supply curve jumps up to injecting liquidity at the Repo rate $\mathrm{R}$. The intersection of the demand and supply curves determines equilibrium. If it takes place between the two stretches market borrowing takes place at the CMR since deficit banks are able to borrow at rates below the RBI Repo rate from surplus banks. Demand could be elastic D or inelastic $D_{i}$ (Figure 1). With the former quantity would adjust more, with the latter interest rates

\footnotetext{
${ }^{1}$ See Walsh (1998) for a development of similar concepts underlying US monetary operating procedures.
} 
were likely to be volatile. If demand shifts up but LTL does not adjust CMR would rise to the Repo rate, and most borrowing would be from the RBI. If Repo transactions are rationed or collateral with the banks is exhausted, the CMR could rise above the Repo rate.

Borio (1997) in surveying the operating procedures of a number of AEs remarks they prefer not to use standing facilities since they want markets to deliver. Maintaining the CMR in the middle of the band with borrowing in markets requires good forecasting of and adjustment of LTL to autonomous liquidity shocks (Guthrie and Wright, 2000). So a channel plus daily OMOs to adjust for shocks work well to anchor market rates in the middle of the band. Reserve requirements also normally give banks time to adjust since they allow maintenance lags and average requirements. Strict maintenance requirement of CRR balances would make for an inelastic $\mathrm{D}_{\mathrm{i}}$. India made it as high as $99 \%$ during the IT period for all days of the reporting fortnight ${ }^{2}$.

Figure 1: The liquidity adjustment facility

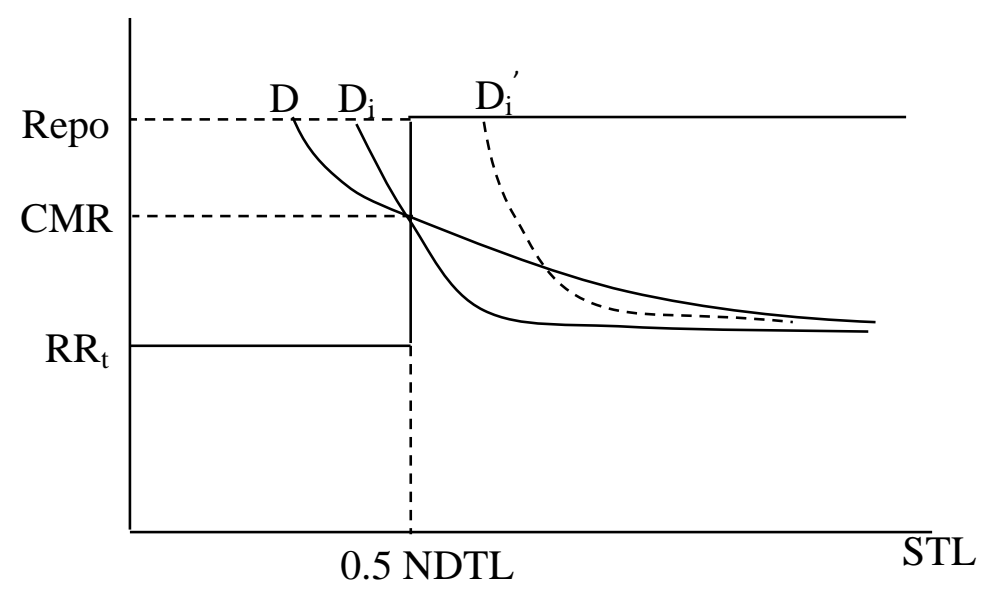

Under an operating procedure that either does not forecast liquidity demand shocks well or does not respond to them, $\mathrm{D}_{\mathrm{i}}$ may shift to $D_{i}^{\prime}$ for a rise in demand. The CMR would rise to the Repo rate, there would be more borrowing from the RBI. Call money market turnover would fall.

Access to the call money market has been restricted only to banks and primary dealers in order to mitigate default risk since it is an uncollateralized market. The CBLO, RBI Repo, marginal standing facility with a rate above the Repo and Reverse Repo all require collateral. Therefore, despite the LAF, system-wide stress in liquidity can persist. Moreover, STL is not a perfect substitute for LTL.

\footnotetext{
${ }^{2}$ In 2010 it used to be a minimum of $70 \%$ of the prescribed CRR balance as on the last Friday of the second preceding fortnight. In July 2013 it was raised to $99 \%$ on all days of the fortnight. In September it was reduced to $95 \%$ and in April 2016 to $90 \%$.
} 
Substituting (2), (3), (4) and the policy response $\Psi^{d}=0$ and $\Psi^{s}=0$ in the equilibrium condition (5) gives:

$$
\begin{aligned}
& T L_{t}=\frac{b}{a+b} \epsilon^{d}<\epsilon^{d} \\
& C M R_{t}=\frac{b}{a+b} \text { Repo }_{t}-\frac{1}{a+b}\left(\epsilon_{t}^{m}+\epsilon_{t}^{d}-\epsilon_{t}^{S}\right)
\end{aligned}
$$

Since $T L^{S}$ adjusts less than the shock to $T L^{d}, C M R_{t}$ shifts up to the Repo. STL, CMR and TL all rise but there is no change in $\mathrm{LTL}^{\mathrm{s}}$.

\section{Literature Review}

In an example of Structural Vector Auto Regression (SVAR) estimation of monetary transmission to the real sector, Khundrakpam and Jain (2012), find monetary policy impacts output with a lag of 2-3 quarters and inflation with a lag of 3-4 quarters, the impact persisting for 8-10 quarters. The CMR interest rate channel is found to be the strongest. It accounts for about half of the total impact of monetary shocks on output growth and about one-third of the total impact on inflation. But effect of CMR on output is 2-3 times greater than its effect on inflation.

While stylized facts (Section 4) show some co-movement of rates in the first leg of transmission to financial market rates, the first leg has rarely been studied rigorously. Kanagasabapathy et.al. (2014) do study the interplay and complementarity between the rate and quantum channels in India, by estimating Granger causality between various sets of variables using monthly data in VAR models. They find the Repo rate has a stronger effect on liquidity than the reverse, but longrun liquidity moves sufficiently independently to partly nullify the effect of the Repo rate on nonfood credit. Their study period, the post LAF period up to May 2012, when liquidity was largely in surplus due to large inflows, may be influencing these results. They also find the Repo rate is more effective in adjusting short run market rates, such as call money market rate and one year GSecs, as compared to long run market rates like 10 year G-Secs, which depend on various other factors like output gap, future economic activity etc. But they do not study transmission at high frequencies.

In the initial stages of LAF, policy changed both price and quantity variables in the same direction. The volatility of call money rates, although reduced, was still appreciable since they 
could jump from one edge of the band to the other and the band itself was wide. When there were large inflows, as in the mid-2000s, the CMR was at the Reverse Repo rate. RBI (2011) concluded from international experience that transmission is better when liquidity is in deficit mode. If banks have to borrow, money market rates respond faster to policy rate shocks. The recommendations were accepted. Liquidity deficit, however, was not to exceed 1 per cent of net demand and time liabilities (NDTL) of commercial banks. Accommodation of liquidity through repo was supplemented with a marginal standing facility (MSF) fixed at 100 basis points above the Repo rate. The MSF would make additional liquidity available up to one per cent of the statutory liquidity ratio (SLR). The report also pointed out, due to large exogenous liquidity shocks from foreign inflows and variations in government cash balances, it is difficult to predict liquidity requirements on a daily basis. Steps were also taken to improve liquidity forecasting and reduce transaction costs in accessing liquidity from the RBI, so as to allow finer tuning of liquidity to requirements and smoother adjustment of market rates. Such fine tuning became all the more imperative with the decision to keep LAF at the injection mode.

Following recommendations of the Patel Committee Report (RBI, 2014), RBI moved to variable rate term repo by restricting borrowing in the fixed rate LAF window to 0.25 per cent of NDTL, with 0.75 made available through term repos. An active term repo market was expected to improve market resilience to liquidity shocks reducing dependence on the RBI, as well as provide benchmarks for pricing a wider range of market products ${ }^{3}$. After a transitional period, the operating target was to shift to the 14-day term repo; the reverse repo was to approach the repo, with the floor of the LAF corridor now provided by a non-collateralized remunerated standing deposit facility. The term repo market, however, did not take off. Banks were reluctant to depend too much on each other since in the absence of a benchmark rate bilateral rates could rise too much.

When the RBI moved to an easing phase in 2015 but with liquidity in deficit, tight liquidity caused severe problems in transmission. Average daily liquidity deficit exceeded 1 per cent of NDTL. Graph 1 shows the LAF to be in injection model where banks were borrowing from the RBI ever since end 2015. There were numerous complaints from markets (Das, 2016). As a result, on April 5, 2016 it was announced market developments were now sufficient to narrow the LAF corridor from 100 to 50 basis points without the CMR overshooting the bounds. The ex-ante liquidity deficit would be reduced over time from 1 per cent of NDTL towards neutrality (RBI

\footnotetext{
${ }^{3}$ Apart from market development, this was conditional on better government cash management, and better liquidity assessment with daily reporting by banks.
} 
2016). Even if long-term liquidity moved towards surplus and the CMR fell towards the Reverse Repo rate, it would not be a large change. But in the second half of 2018 again there were large persistent liquidity deficits with borrowing in the LAF (Das, 2018).

This period of experimentation with LAF offers rich data points to test hypotheses about the interaction of interest rates with short and long-term liquidity. Results could be useful inputs in policy design.

China is another country with monetary systems in transition. Qiao and Liu (2017) in a detailed event-window regression analysis of the interaction between the Central Bank target rate and its Open Market Operations found the effectiveness of the target rate change is conditional on a change in liquidity in the same direction, especially in a loosening cycle. They surmise this may be because of the clear and strong signal market operators then receive. We do a similar analysis of the Indian economy, while making the additional distinction between short- and long-term liquidity.

\section{Stylized Facts from Data}

Our data covers the active LAF period from April 2002 onwards to March 2018, and is sourced from Database on Indian Economy (DBIE), Weekly Statistical Supplement (WSS) of the RBI, and EPWRFITS of the EPW Research Foundation. All the rates are in per cent per annum and the liquidity figures are in Rupees crore. Key monetary concepts used are explained in Table 2a. Table $2 \mathrm{~b}$ collects all the abbreviations.

Repo (repurchase) transactions are reversible overnight and therefore affect only short-term liquidity. Term repos are also short-term but largely for 7, 14 or 28 days. When RBI buys a GSec, for example, it increases money supply so this is an injection of liquidity. Selling a G-Sec has the reverse effect and therefore is said to absorb liquidity. To measure STL, purchase and sale data for Repo, Reverse Repo, Term Repo, Term Reverse Repo and MSF was taken and Net

Injection (+)/Absorption (-) was calculated as a difference between Repo and Reverse Repo transactions for both Spot and Term LAF. 


\begin{tabular}{|c|c|}
\hline \multicolumn{2}{|r|}{ Table 2a: Monetary concepts } \\
\hline VARIABLE NAME & DESCRIPTION \\
\hline Repo Rate & $\begin{array}{l}\text { Repo rate is the policy interest rate, which was introduced in } 2002 \text {. It is the rate } \\
\text { at which RBI lends to banks for overnight/short-term credit requirements to } \\
\text { manage mismatches between the demand and supply of funds. }\end{array}$ \\
\hline Call Money Market & $\begin{array}{l}\text { Call Money Market refers to the market where surplus funds are traded at } \\
\text { interbank rates with the purpose of managing temporary mismatches in funds } \\
\text { and/or to meet CRR and SLR requirements mandated by RBI. }\end{array}$ \\
\hline $\begin{array}{l}\text { Collateralized Borrowing and } \\
\text { Lending Obligation }\end{array}$ & $\begin{array}{l}\text { CBLO is a money market instrument that facilitates borrowing and lending of } \\
\text { funds in a collateralized environment with various maturity tenors. }\end{array}$ \\
\hline Treasury Bills and G-Secs & $\begin{array}{l}\text { Treasury Bills are instruments used to fulfil short term money borrowing needs } \\
\text { of the Government. They are very secure and are highly marketable and } \\
\text { tradable. T-Bills for various maturities are traded in secondary markets. G-Secs } \\
\text { are longer maturity borrowings. }\end{array}$ \\
\hline $\begin{array}{l}\text { Liquidity Adjustment Facility } \\
\text { (injection + and absorption -) }\end{array}$ & $\begin{array}{l}\text { LAF uses collateralized repurchase agreements (repos) to make overnight and } \\
\text { short-term loans to banks thus injecting liquidity. Reverse repos absorb } \\
\text { liquidity. }\end{array}$ \\
\hline Cash Reserve Ratio & $\begin{array}{l}\text { CRR contribute to monetary control since banks are required to set aside a } \\
\text { portion of their total deposits as reserves with the RBI, thus reducing their } \\
\text { ability to lend. }\end{array}$ \\
\hline Open Market Operations & $\begin{array}{l}\text { OMOs are buying and selling of G-Secs by RBI to manage long term liquidity. } \\
\text { Buying securities injects (+) long term liquidity and selling securities results in } \\
\text { absorption (-) of the same on an enduring basis. }\end{array}$ \\
\hline $\begin{array}{l}\text { Foreign Exchange } \text { Market } \\
\text { Intervention }\end{array}$ & $\begin{array}{l}\text { Buying and selling of foreign assets affects foreign reserves. There is liquidity } \\
\text { injection when foreign currency is purchased and absorption when foreign } \\
\text { currency is sold. If liquidity injection is sterilized by sale of G-Secs it implies a } \\
\text { swap of G-Secs for foreign securities in the RBI's balance sheet. }\end{array}$ \\
\hline Market Stabilisation Scheme & $\begin{array}{l}\text { MSS was introduced in } 2004 \text { as an instrument to sterilize excess liquidity } \\
\text { generated when RBI purchased foreign currency following large foreign } \\
\text { capital inflows after } 2002 \text { in order to overcome shortage of G-Secs. RBI sells } \\
\text { G-Secs outside the normal borrowing programme and deposits the proceeds in } \\
\text { a separate MSS account to be used during buy backs/redemption of securities } \\
\text { issued under MSS. }\end{array}$ \\
\hline Marginal Standing Facility & $\begin{array}{l}\text { MSF created in } 2011 \text { allows banks to borrow overnight funds from RBI against } \\
\text { approved government securities at a rate higher than the Repo in the LAF } \\
\text { window. }\end{array}$ \\
\hline
\end{tabular}

For LTL Net Injection (+) from OMO is the difference between purchase and sale of government securities. Net Absorption (-) is net sales. Data on change in foreign currency (FX) assets proxies for RBI FX market intervention. Increase in FX assets injects liquidity as the RBI pays for its acquisition of foreign currency with domestic currency and vice-versa as decrease in FX assets absorbs liquidity. Change in Bankers' Deposits with RBI is used to proxy for liquidity injection or absorption from CRR operations. There is liquidity injection when deposits in RBI decrease and vice versa. Finally, deposits in MSS account (from WSS) capture liquidity injection or absorption through MSS. An increase in deposits is taken as absorption and vice versa. Total liquidity has been derived as a summation of Net Injections (+)/Absorptions (-) through LAF, MSF, OMO, CRR, MSS and FX market intervention. Long term liquidity (LTL) is total liquidity minus short term liquidity created in the LAF. 


\section{Table 2b: Abbreviations}

\begin{tabular}{ll}
\hline 1 Year G-Secs & 1 Year Government Securities \\
91Day T-Bills & 91 Day Treasury Bills \\
AEs & Advanced Economies \\
CBLO & Collateralized Borrowing and Lending Obligations \\
CD & Certificates of Deposit \\
CMR & Call Money Rate \\
CP & Commercial Papers \\
CRR & Cash Reserve Requirement \\
DBIE & Database on Indian Economy \\
EPWRFITS & Economic and Political Weekly Research Foundation India Time Series \\
FX & Foreign Exchange \\
GDP & Gross Domestic Product \\
GFC & Global Financial Crisis \\
G-Secs & Government Securities \\
LAF & Liquidity Adjustment Facility \\
MSF & Marginal Standing Facility \\
MSS & Market Stabilisation Scheme \\
NDTL & Net Demand and Time Liabilities \\
OMO & Open Market Operations \\
PLR & Prime Lending Rate \\
RBI & Reserve Bank of India \\
SVAR & Structural VAR \\
VAR & Vector Auto Regression \\
WSS & Weekly Statistical Supplement \\
\hline
\end{tabular}

\subsection{Stylized Facts: Easing and Tightening Phases}

\begin{tabular}{|c|c|c|c|c|c|c|c|}
\hline \multicolumn{8}{|c|}{ Table 3a: Monthly liquidity operations } \\
\hline Phases & $\begin{array}{l}\text { Easing } \\
\text { Phase (Apr } \\
2002 \text { to } \\
\text { Oct 2005) }\end{array}$ & $\begin{array}{l}\text { Tightening } \\
\text { Phase (Nov } \\
2005 \text { to } \\
\text { Oct 2008) }\end{array}$ & $\begin{array}{l}\text { Easing } \\
\text { Phase (Nov } \\
2008 \text { to } \\
\text { March } \\
\text { 2010) }\end{array}$ & $\begin{array}{l}\text { Tightening } \\
\text { Phase (Apr } \\
2010 \text { to } \\
\text { Apr 2012) }\end{array}$ & $\begin{array}{l}\text { Easing } \\
\text { Phase (May } \\
\text { 2012 to Sep } \\
\text { 2013) }\end{array}$ & $\begin{array}{l}\text { Tightening } \\
\text { Phase (Oct } \\
2013 \text { to Jan } \\
\text { 2015) }\end{array}$ & $\begin{array}{l}\text { Easing } \\
\text { Phase (Feb } \\
2015 \text { to } \\
\text { Mar 2018) }\end{array}$ \\
\hline Time Duration (months) & 43 & 36 & 17 & 25 & 17 & 26 & 27 \\
\hline Change in Repo & 8.00 to 6.00 & 6.00 to 9.00 & 9.00 to 4.75 & 4.75 to 8.5 & 8.5 to 7.25 & 7.25 to 8.00 & 8.00 to 6.00 \\
\hline No. of Times Changed & 4 & 10 & 6 & 13 & 4 & 3 & 7 \\
\hline Basis Points & -200 & 300 & -425 & 325 & -125 & 75 & -200 \\
\hline LAF (Net Injection (+)/Absorption (-)) & 6103872 & -2317386 & -23132185 & 26767905.5 & 25205282 & 6975521 & -16872687 \\
\hline $\begin{array}{l}\text { OMO (Net Purchase of Securities (+)/Sale } \\
(-))\end{array}$ & -94498 & 19018 & 150800 & 210796 & 177757.13 & -34775 & 71678 \\
\hline $\begin{array}{l}\text { Net RBI Intervention in FX Market (Net } \\
\text { Purchase of Foreign Assets (+)/Sales (-)) }\end{array}$ & 368228 & 671788 & -128912 & 170138 & 246590 & 262350 & 755950 \\
\hline CRR (Net Injection (+)/Absorption (-)) & -33138.00 & -144369.00 & -33378.00 & -17327.00 & -62695.00 & 11134.00 & -201605.00 \\
\hline MSS (Net Injection (+)/Absorption (-)) & -69255 & -100250 & 166760 & 2737 & 0 & 0 & 0 \\
\hline MSF (Net Injection (+)/Absorption (-)) & 0 & 0 & 0 & 0 & 81084 & -80504 & 920 \\
\hline Long term liquidity & 171337.00 & 446187.00 & 155270.00 & 366344.00 & 442736.13 & 158205.00 & 626943.00 \\
\hline Total liquidity & 6275209 & -1871199 & -22976915 & 27134249.5 & 25648018.13 & 7133726 & -16245744 \\
\hline
\end{tabular}

The period under study can be divided into seven phases of easing and tightening corresponding to continuous fall or increase in policy Repo rate respectively. There were four easing and three 
tightening phases. Phase I, an easing phase, runs from April 2002 to October 2005. The final Phase VII from February 2015 to March 2018 is also an easing phase (Table 3a,b).

The duration of the cycles range from 25 months to as long as 43 months. The shortest phases were III and V. Phase III was the post Global Financial Crisis (GFC) stimulus. Gross Domestic Product (GDP) growth hit a decade low of 5 per cent in 2012-2013 (Phase V). RBI, therefore, followed an accommodating monetary stance in this period, which was reversed by the move towards inflation targeting.

\begin{tabular}{|c|c|c|c|c|c|c|c|}
\hline Phases & $\begin{array}{l}\text { Easing Phase } \\
\text { 2002-05 }\end{array}$ & $\begin{array}{l}\text { Tightening } \\
\text { Phase 2005- } \\
08 \\
\end{array}$ & $\begin{array}{l}\text { Easing Phase } \\
\text { 2008-10 }\end{array}$ & $\begin{array}{l}\text { Tightening } \\
\text { Phase } \\
\text { 2010-12 } \\
\end{array}$ & $\begin{array}{l}\text { Easing } \\
\text { Phase } \\
\text { 2012-13 } \\
\end{array}$ & $\begin{array}{l}\text { Tightening } \\
\text { Phase 2013- } \\
14 \\
\end{array}$ & $\begin{array}{l}\text { Easing } \\
\text { Phase } \\
\text { 2014-18 } \\
\end{array}$ \\
\hline $\begin{array}{l}\text { LAF (Net Injection } \\
(+) / A b s o r p t i o n(-)\end{array}$ & 9364782 & -7023996 & -21779135 & 26160475.5 & 20469885 & 11110611 & -14000217 \\
\hline $\begin{array}{l}\text { OMO (Net Purchase of } \\
\text { Securities }(+) / \text { Sale }(-))\end{array}$ & -91940 & -2766 & 170020 & 201332 & 154601.13 & 58234 & 11295 \\
\hline $\begin{array}{l}\text { Net RBI Intervention in } \\
\text { FX Market (Net } \\
\text { Purchase +/Sales-) }\end{array}$ & 344003 & 602902 & -46373 & 180861 & 82119 & 248280 & 936660 \\
\hline $\begin{array}{l}\text { CRR (Net Injection } \\
\text { (+)/Absorption (-) }\end{array}$ & -29849.13 & -214451.06 & -23851.41 & -3992.803 & 35620.2212 & -109031.656 & -135822.16 \\
\hline $\begin{array}{l}\text { MSS (Net Injection } \\
(+) / \text { Absorption (-) }\end{array}$ & -64211 & -104181 & 165655 & 2737 & 0 & 0 & 0 \\
\hline $\begin{array}{l}\text { MSF (Net Injection } \\
(+) / A b s o r p t i o n ~(-)\end{array}$ & 0 & 0 & 0 & 0 & 7000 & 14929 & -20429 \\
\hline Long term liquidity & 158002.87 & 281503.94 & 265450.59 & 380937.197 & 279340.351 & 212411.344 & 791703.838 \\
\hline Total liquidity & 9522784.87 & -6742492.06 & -21513684 & 26541412.7 & 20749225.4 & 11323022.34 & -13208513 \\
\hline
\end{tabular}

LTL remained in the net injection mode throughout the period while total liquidity had both injection and absorption phases. Therefore LAF had a major impact on liquidity conditions in the economy. The policy rate and durable liquidity have often not worked in the same direction after 2011. The Repo rate was reduced while LTL was kept tight. LAF liquidity was not always in surplus during easing phases or vice versa.

Graphs 1-3 present monthly and annual data to give a clear stylized picture compared to the noisy daily data used in the regression. LAF operations depended on the amount of LTL. Between 2003 and 2009 large capital flows and the post GFC stimulus kept LTL in surplus requiring absorption in the LAF regardless of the monetary cycle (Graph 1). Over 2010-15, there was a conscious decision to keep LAF in deficit whatever the phase of the cycle. 


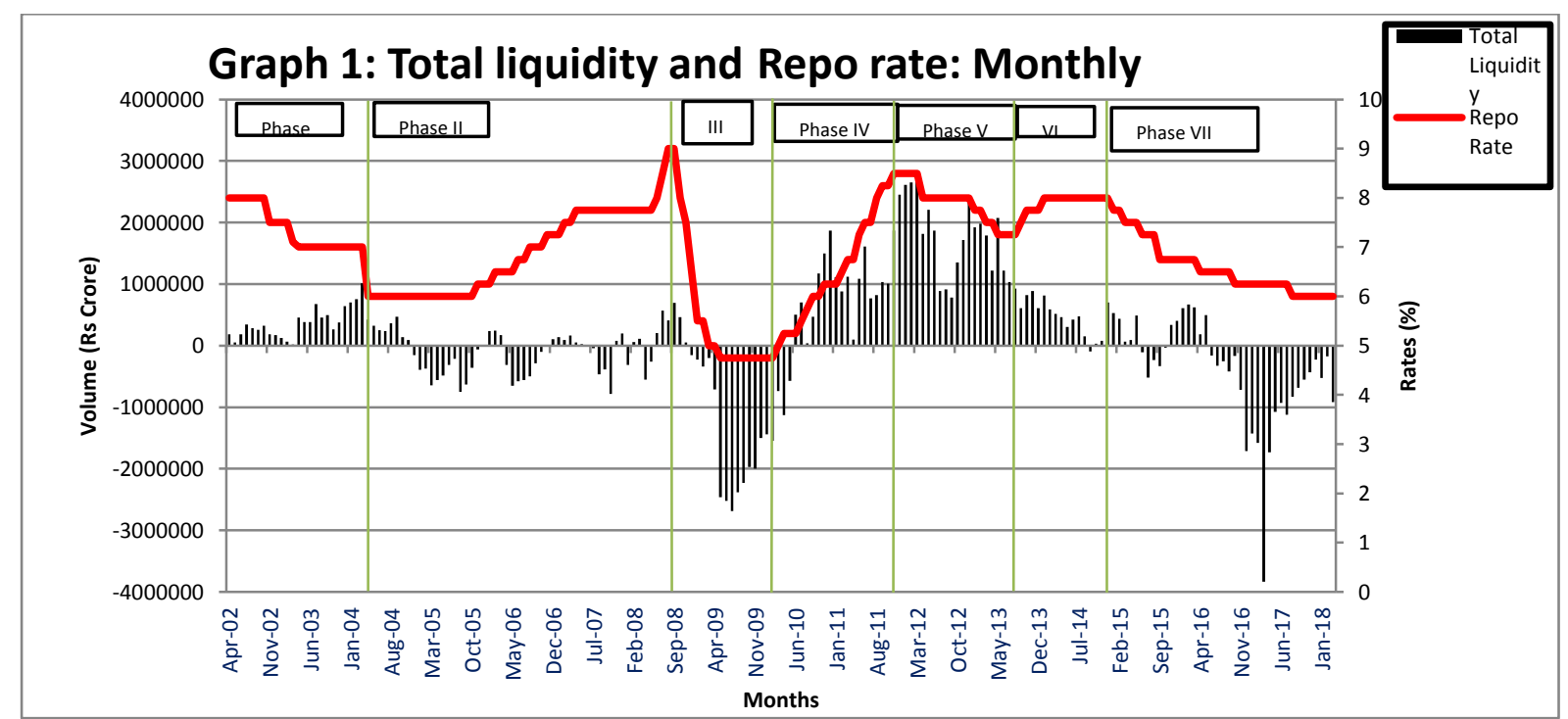

Notes: RHS Y-axis is the Repo rate in percentage and the LHS Y-axis is volume of total liquidity in Rupees Crores. Phase I, III, V, VII are easing phases and II, IV, VI are tightening phases respectively. It shows the interaction between the price and quantum channels of transmission for the phases. Red line is the Repo rate over the phases and the black bar chart shows the total liquidity volumes for the phases.

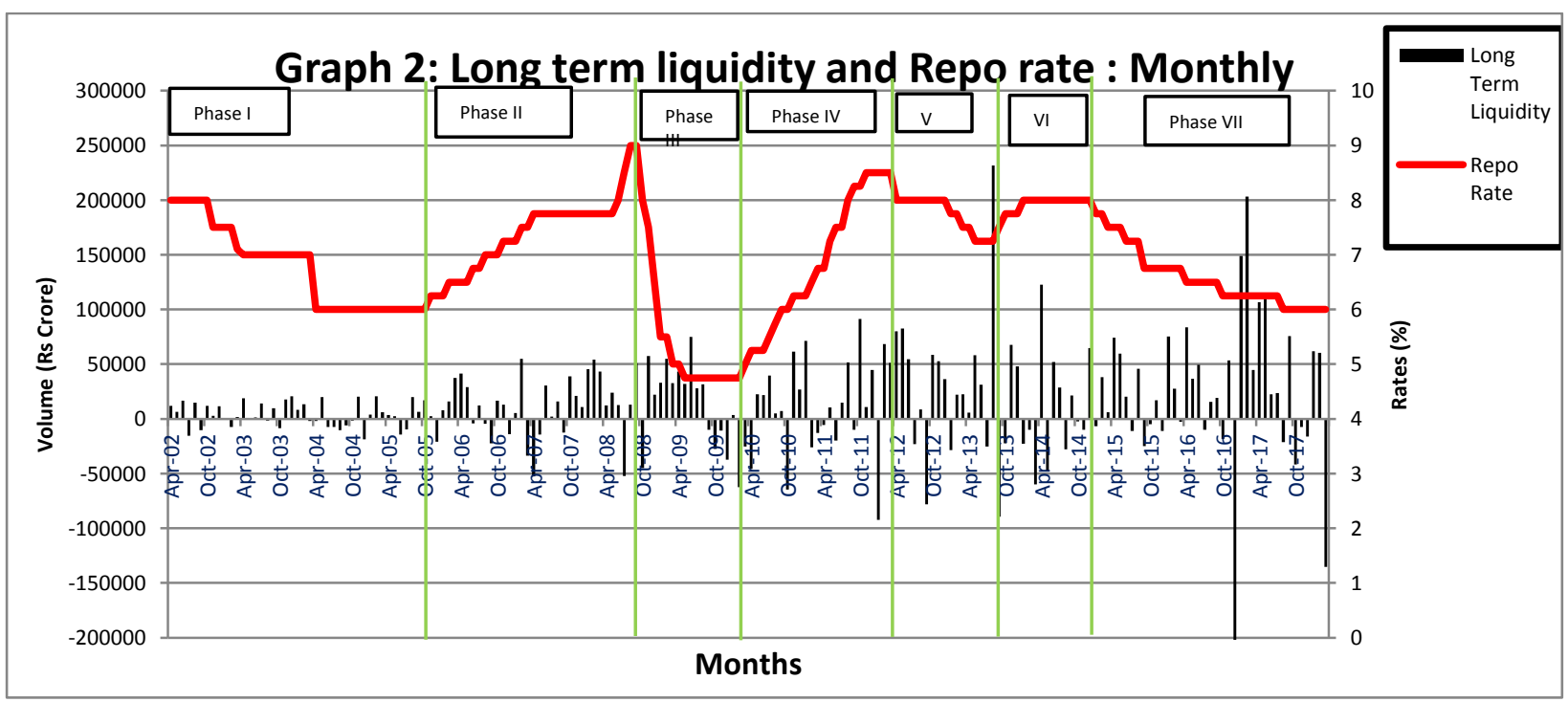

Notes: RHS Y-axis is the Repo rate in percentage and the LHS Y-axis is volume of long term liquidity in Rupees Crores. Phase I, III, V, VII are easing phases and II, IV, VI are tightening phases respectively.

Irrespective of the phases, there were net injections of LTL for most of the period, albeit at low levels, to meet the needs of a growing economy (Graphs 2 and 3). The size of intervention increased over the years with the size of the economy. In 2016 following demonetisation, which brought huge amounts of cash into the banking system, there was major liquidity absorption through LTL as well as LAF channels. Large inflows in 2017 increased long-term liquidity again requiring absorption later in the year. 


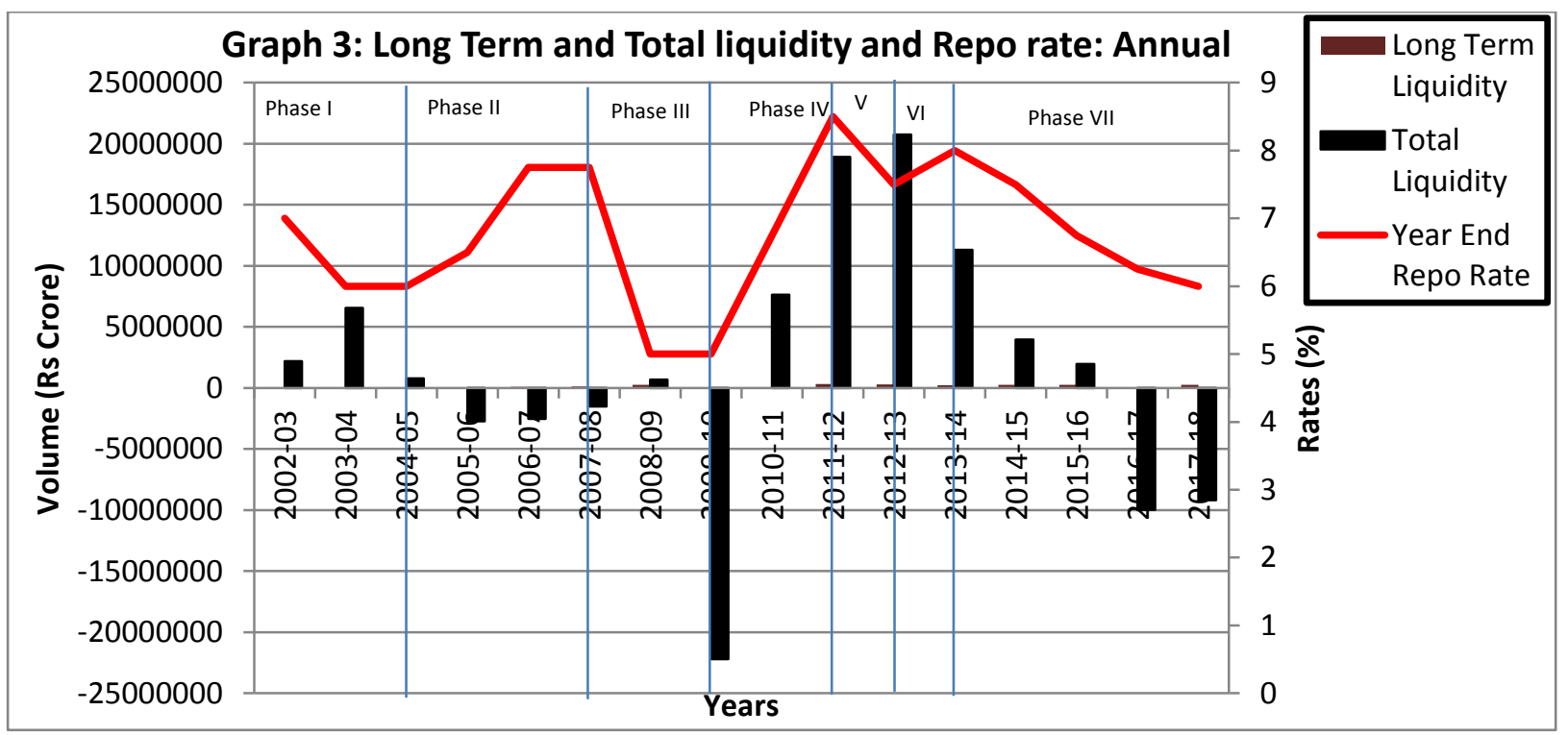

Notes: The brown bar chart is the symbol used for long term liquidity and the black bar chart is the total liquidity. The red line shows the Repo rate changes. Total liquidity is a sum of Net Injection (+)/ Absorption (-) from Repo, Term Repo, CRR, Foreign Market Intervention of RBI, MSS, OMO and MSF. LTL is a sum of Net Injection (+)/ Absorption (-) from CRR, Foreign Market Intervention of RBI, MSS, OMO and MSF.

Graph 3 shows long term and total liquidity for annual data. As in the high frequency data, LTL is positive for the entire period while total liquidity switches from absorption to injection. Amounts were much higher in the post GFC period. But injections shrank over 2013-16. The absolute value of the ratio of LTL to total liquidity is very low implying that LAF was the dominant source of liquidity (Table 3a, b). The model in Section 2 suggests this is to be expected under large exogenous shocks to liquidity demand, which policy did not accommodate with LTL. It would also explain why Repo transactions became much larger than those in the call money market.

\subsection{Stylized facts: Repo Rate and Market Interest Rates}

Larger alteration in Repo rate causes most of the rates to move in the same direction (Table 4). In Phases V and VI, which had the lowest adjustment compared to other phases, the market rates did not adjust in the same direction as the Repo rate (the LAF was in deficit despite an easing cycle, in Phase V). Over the years, adjustment of 91 Day T-Bills and to some extent 1 Year G-Secs increased in absolute terms but 10 Year G-Secs did not follow the same pattern. This follows since long-term market rates are influenced by other factors like present and future economic activities, output gap, fiscal policy and the global environment. Among other rates, CD Rate (low rate), $\mathrm{CP}$ and $\mathrm{CMR}$ show adjustment to changes in the policy rate, but their volatility is also high. The Prime Lending Rate (PLR), which is closer to an upper bound of bank lending rates, was the benchmark rate banks had to announce until July 2010. After that the benchmark was the Base Rate, which is closer to a minimum lending rate. Bank lending rates also follow the Repo rate, but less than market rates do and generally more during tightening compared to loosening episodes. 
The Base Rate, however, did not rise with the Repo rate in the tightening phase VI. It has been falling since 2013, through a period of industrial slowdown and low credit growth.

\begin{tabular}{|c|c|c|c|c|c|c|c|c|c|c|c|c|c|c|}
\hline & $\mathbf{I}$ & & II & & III & & IV & & $\mathbf{V}$ & & VI & & VII & \\
\hline Phases & $\begin{array}{l}\text { Easing } \\
\text { Phase } \\
\text { (Apr } \\
\text { 2002- Oct } \\
\text { 2005) }\end{array}$ & BPS & $\begin{array}{l}\text { Tightenin } \\
\text { g Phase } \\
\text { (Nov2005- } \\
\text { Oct 2008) }\end{array}$ & BPS & $\begin{array}{l}\text { Easing } \\
\text { Phase } \\
\text { (Nov } \\
\text { 2008- } \\
\text { March } \\
\text { 2010) } \\
\end{array}$ & BPS & $\begin{array}{l}\text { Tightenin } \\
\text { g Phase } \\
\text { (Apr } \\
\text { 2010-Apr } \\
\text { 2012) }\end{array}$ & BPS & $\begin{array}{l}\text { Easing } \\
\text { Phase } \\
\text { (May } \\
\text { 2012-Sep } \\
\text { 2013) }\end{array}$ & BPS & $\begin{array}{l}\text { Tightenin } \\
\text { g Phase } \\
\text { (Oct 2013- } \\
\text { Jan 2015) }\end{array}$ & BPS & $\begin{array}{l}\text { Easing } \\
\text { Phase } \\
\text { (Feb 2015- } \\
\text { Mar 2018) }\end{array}$ & BPS \\
\hline $\begin{array}{l}\text { Time Duration } \\
\text { (months) }\end{array}$ & 43 & & 36 & & 17 & & 25 & & 17 & & 26 & & 27 & \\
\hline $\begin{array}{l}\text { Change in } \\
\text { Repo }\end{array}$ & $8.00-6.00$ & -200 & $6.00-9.00$ & 300 & $\begin{array}{l}9.00- \\
4.75\end{array}$ & -425 & $4.75-8.5$ & 325 & $8.5-7.25$ & -125 & $7.25-8.00$ & 75 & $8.00-6.00$ & -200 \\
\hline \multicolumn{15}{|l|}{$\begin{array}{l}\text { Change in Call } \\
\text { Money Market } \\
\text { Rate }\end{array}$} \\
\hline Borrowing & $6.51-5.12$ & -139 & $5.29-4.16$ & -113 & $\begin{array}{l}6.78- \\
3.34\end{array}$ & -344 & $3.47-8.82$ & 535 & $8.81-10.26$ & 145 & $9.08-8.11$ & -97 & $7.88-6.14$ & -174 \\
\hline Lending & $6.65-5.12$ & -153 & $5.29-4.16$ & -113 & $\begin{array}{l}6.78- \\
3.34\end{array}$ & -344 & $3.47-8.82$ & 535 & $8.81-10.26$ & 145 & $9.08-8.11$ & -97 & $7.88-6.14$ & -174 \\
\hline \multicolumn{15}{|l|}{$\begin{array}{l}\text { Change in CD } \\
\text { Rate }\end{array}$} \\
\hline Low & $5-4.66$ & -34 & $5.25-8.92$ & 367 & $8.8-4$ & -480 & $4.52-9.34$ & 482 & $9-9.37$ & 37 & $9.16-8.3$ & -86 & $8.06-6.65$ & -141 \\
\hline High & $10.88-7.75$ & -313 & $7.75-21$ & -754 & $\begin{array}{l}12.9- \\
7.36\end{array}$ & -554 & $7.12-12$ & 488 & $10.6-11.95$ & 135 & $11.95-8.67$ & -328 & $8.65-8.5$ & -15 \\
\hline \multicolumn{15}{|l|}{$\begin{array}{l}\text { Change in CP } \\
\text { Rate }\end{array}$} \\
\hline Low & $7.6-5.69$ & -191 & 5.63-11.9 & 627 & $11.55-4$ & -755 & $5.3-8.51$ & 321 & $8.02-8.17$ & 15 & $9.5-7.98$ & -152 & 8.06-6.49 & -157 \\
\hline High & $11.1-7.5$ & -360 & $7.5-17.75$ & 1025 & $16.9-8.9$ & -800 & $9-14.5$ & 550 & $14.25-13.8$ & -45 & $\begin{array}{l}13.57- \\
12.61\end{array}$ & -96 & $11.73-14$ & 227 \\
\hline $\begin{array}{l}\text { Change in } \\
\text { CBLO }\end{array}$ & $3.55-5.09^{\mathrm{a}}$ & 154 & $5.05-4.08$ & -97 & $\begin{array}{l}5.32- \\
3.27\end{array}$ & -205 & $3.05-8.5$ & 545 & $8.39-10.22$ & 183 & $7.76-8.32$ & 56 & $8.02-4.6$ & -342 \\
\hline $\begin{array}{l}\text { Change in } 91 \\
\text { Day TB }\end{array}$ & $5.85-5.47$ & -38 & $5.41-7.43$ & 202 & $7.05-4.3$ & -275 & $4.25-8.59$ & 434 & $8.37-9.9$ & 153 & $9.84-8.15$ & -169 & $7.92-6.08^{b}$ & -184 \\
\hline $\begin{array}{l}\text { Change in } 1 \\
\text { Year G-Secs }\end{array}$ & $5.68-5.78$ & 10 & $5.8-7.8$ & 200 & $\begin{array}{l}7.47- \\
5.38\end{array}$ & -209 & $5.25-8.12$ & -287 & $7.97-9.58$ & 161 & $12.29-8.01$ & -428 & $7.77-6.65^{\mathrm{b}}$ & -112 \\
\hline $\begin{array}{l}\text { Change in } 10 \\
\text { Year G-Secs }\end{array}$ & $7.23-7.14$ & -9 & $7.14-7.73$ & 59 & $\begin{array}{l}7.85- \\
7.88\end{array}$ & 3 & $7.87-8.50$ & -63 & $8.45-8.18$ & -27 & $8.35-7.98$ & -37 & $7.88-7.72^{b}$ & -16 \\
\hline \multicolumn{15}{|l|}{$\begin{array}{l}\text { Change in } \\
\text { PLR/Base Rate }\end{array}$} \\
\hline Low & $11-10.25$ & -75 & $\begin{array}{l}10.25- \\
13.75\end{array}$ & 350 & $13-11$ & -200 & $11-10$ & -100 & $10-9.80$ & -20 & $10-10$ & 0 & $10-8.65$ & -135 \\
\hline High & $12-10.75$ & -125 & $10.75-14$ & 325 & $13.5-12$ & -150 & $12-10.75$ & -125 & $10.5-10.25$ & -25 & $\begin{array}{l}10.25- \\
10.25\end{array}$ & 0 & $10.25-9.45$ & -80 \\
\hline
\end{tabular}

Notes: PLR or Prime Lending Rate is the interest rate at which banks offer loans to its customers. Base rate is a minimum rate below which rate banks cannot lend. The regulated signal rate switched from Base rate to PLR in 2010; ${ }^{\mathrm{a}}$ Rates are from January, 2004; ${ }^{\mathrm{b}}$ Rates are till February, 2018.

Source: Self computed using data from EPWRFITS, WSS and DBIE

Surplus LTL and the LAF in absorption mode meant the overnight CMR stayed closer to the Reverse Repo rate until 2010, after which the deficit mode kept it closer to the Repo rate. Large exogenous shocks implied collateralized liquidity injection through the Repo was inadequate so that the CMR overshot the LAF bounds, although this became rarer in later years (Graph 4). 


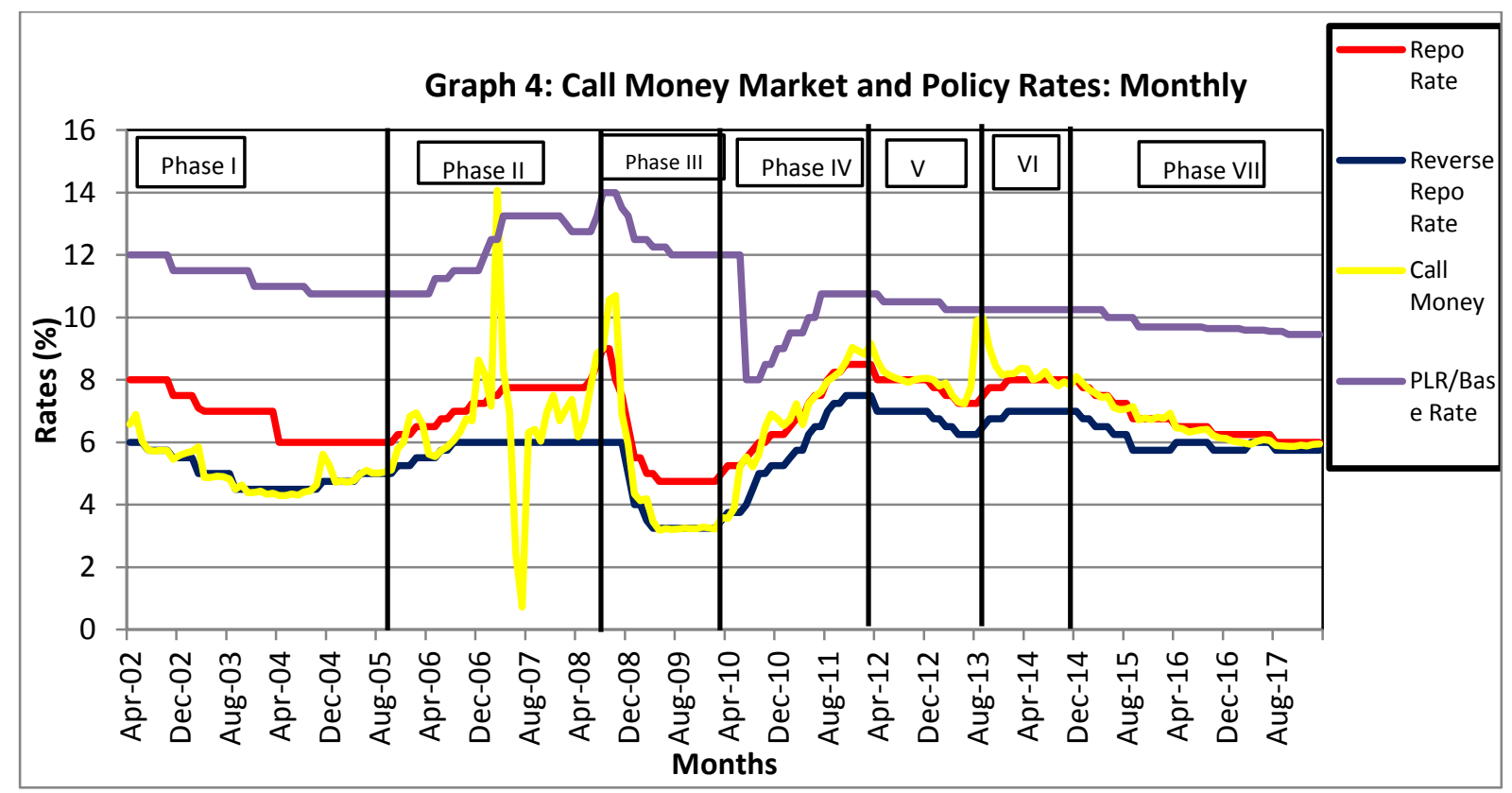

Note: Red, dark blue and yellow lines display Repo, Reverse repo and Call Money Rates respectively.

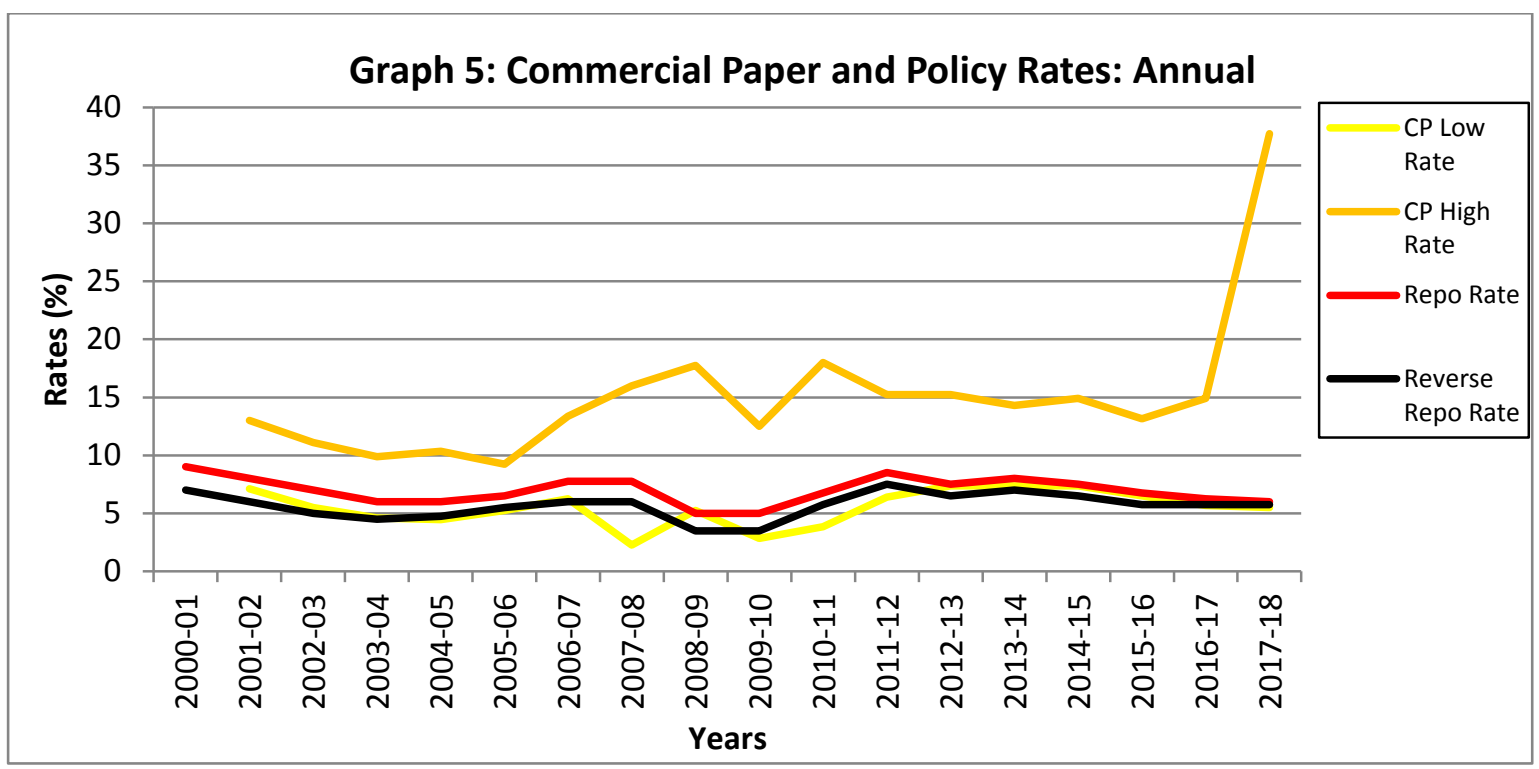

Note: Red, dark blue and yellow lines display Repo, Reverse repo and CP rates respectively.

Other rates show a similar picture with some variations, however. For example, the dispersion band of low and high CP rates, around the LAF band widened over the years. These rates still shows large volatility (Graph 5) that could be due to variations in credit risk. The CBLO rates reached and sometimes exceeded the top of the LAF band in the liquidity deficit period of 2012 (Graph 6). 


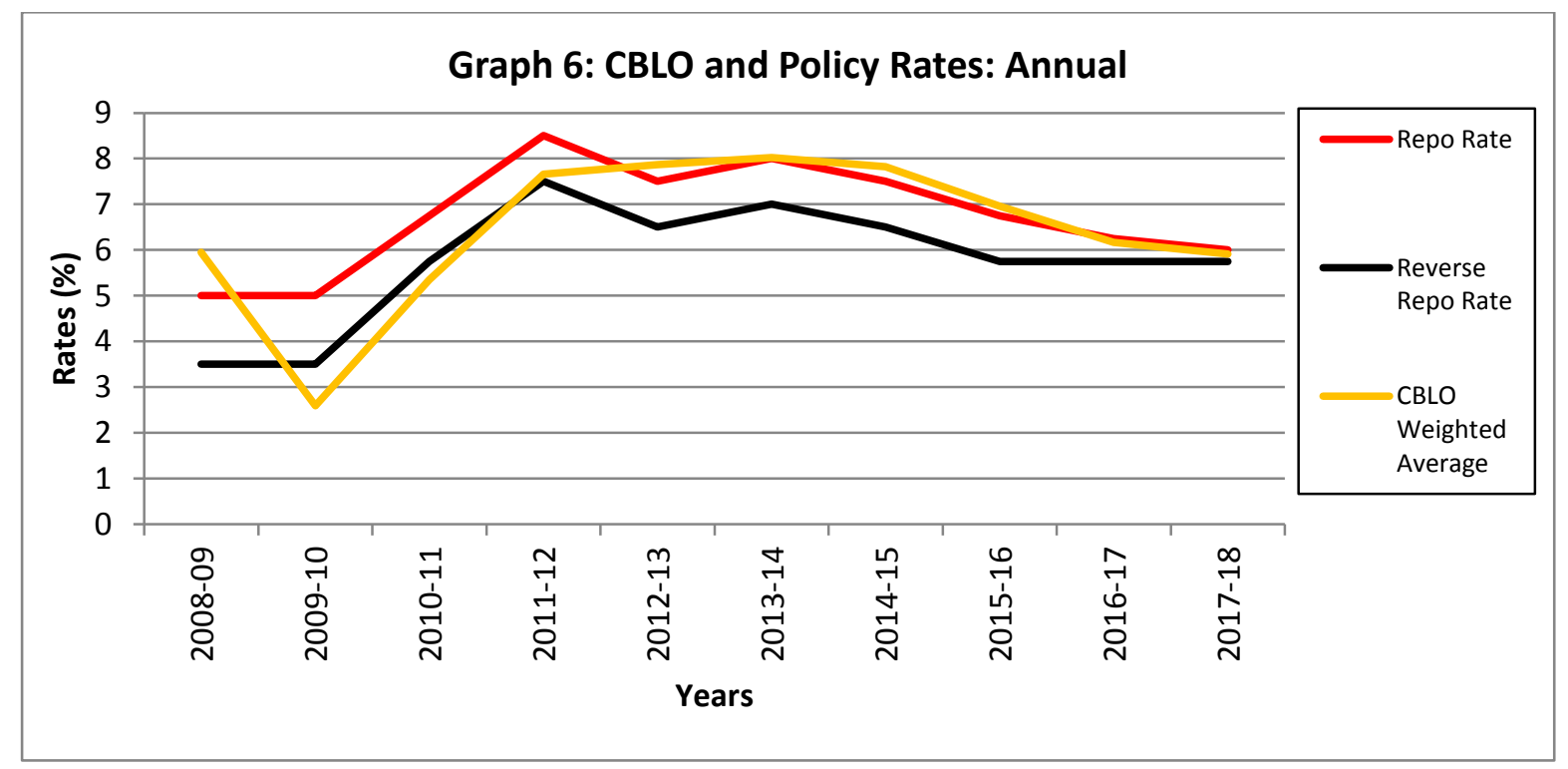

Note: Red, dark blue and yellow lines display Repo, Reverse repo and CBLO rates respectively.

Before 2010, CD rates were erratic, and did not respond much to the policy rate changes (Graph 7). After 2011, the band of dispersion of high and low CD rates from the policy rate has become narrower.

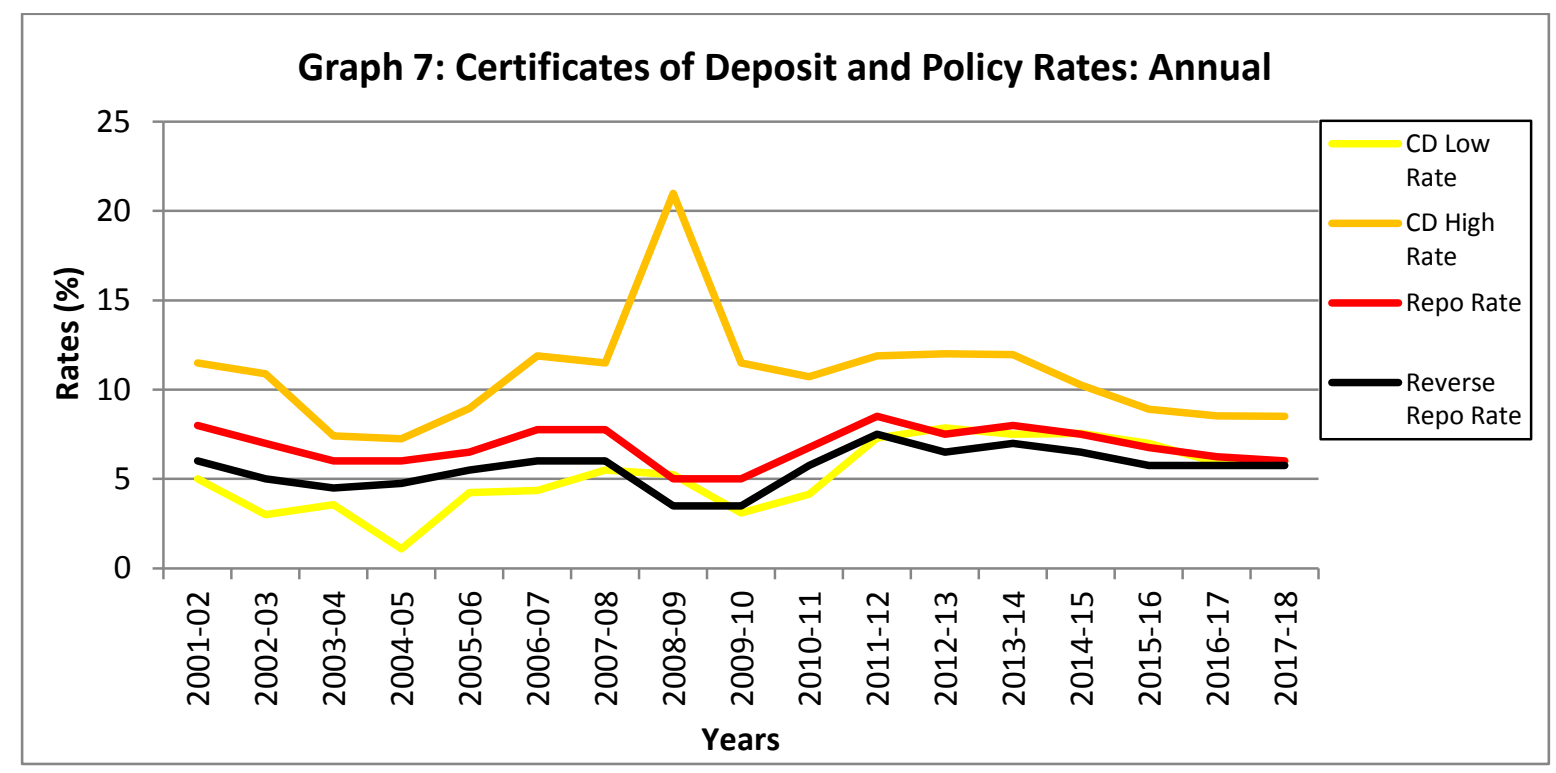

Notes: Red, dark blue and yellow lines display Repo, Reverse repo and CD rates respectively.

\section{Methodology and Estimation}

We next turn to regression analysis of $\mathrm{T}$ and $\mathrm{T} \pm 5$ event windows of Repo rate change to estimate transmission to other market rates. Our strategy is to start with a baseline model, in which we take change in the Repo rate as our primary independent variable and test if its coefficient is significant when changes in other market rates are regressed on it turn by turn. Then we sequentially introduce other variables. First, a dummy for Repo rate increases to test if there is any asymmetry 
in pass through between increase and decrease in Repo rate. Second, to analyse the efficacy of pass through when LAF is in injection mode, denoting total liquidity deficit, and also when LTL is being reduced ${ }^{4}$. Liquidity is injected in the LAF when total liquidity is in deficit. So although the transaction itself increases liquidity, the dummy variable is used as positive for LAF injections in the regressions to capture periods of total liquidity deficit. But OMO sale (absorption) of GSecs is used to indicate liquidity tightening since it directly reduces LTL. Third, we see if transmission is better when quantity variables are in sync with the Repo rate- that is, durable liquidity is tightening (easing) when the Repo rate is rising (falling). Last, we assess the relative effectiveness of short versus long term liquidity and how LAF variables perform relative to total liquidity.

OLS is used to estimate the impact of a change in the Repo rate, liquidity and other variables on change in different market rates ${ }^{5}$. The regressions are estimated using STATA.

\begin{tabular}{ll}
\hline & \multicolumn{1}{c}{ Table 5a: Variable definitions } \\
\hline CPIIR_1Y & Annualized one-year ahead CPI inflation (monthly) \\
D1Y & Change in 1 Year Government Securities on announcement days \\
D10Y & Change in 10 Year Government Securities on announcement days \\
D91D & 91 Day T-Bills changes on announcement days \\
DCBLO & Collateralized Borrowing and Lending Obligations Rate on the announcement days \\
DCMR & Change in Call Money Rate on announcement days \\
DFF & Change in US federal fund rate \\
DRepo & Change in Repo rate changes around the announcement dates \\
DR_LAFVD & The interaction between Repo rate change (DR) and LAF Dummy (LAFVD) \\
DR_RD & Interaction between Repo rate changes (DR) and Repo rate Dummy (RD) \\
DR_TLVD & The interaction between Repo rate change (DR) and Total liquidity Dummy \\
FDRatio & (TLVD) \\
IIPGR_1Y & Ratio of fiscal deficit to GDP (monthly) \\
LAFVD & Annualized one-year ahead industry growth rate (monthly) \\
LR1 & LAFVD takes the value 1 if LAF is in injection mode and 0 otherwise \\
LR2 & Liquidity Ratio LAF/TL \\
LTL & Liquidity Ratio LAF/LTL \\
OMOM1 & Long term liquidity \\
RD & OMO ratio to narrow money, absorption (sale) as plus \\
SLR_EX & Repo Rate Dummy = 1 when rate rises \\
STL & Excess of SLR over mandated ratio (yearly) \\
TL & Short term liquidity created in the LAF \\
TLVD & Total liquidity \\
\hline
\end{tabular}

Event studies are intensively used in the field of corporate finance to study the impact of specific shocks on corporate profits or on financial returns (Khotari and Warner 2016). The assumption of

\footnotetext{
${ }^{4}$ In periods of large inflows, FX operations before one week might have flooded the market with liquidity. Since the window is limited to $t \pm 5$ days, tightening Repo rate may not be transmitted to other market rates in such a situation. That is another reason it is helpful to control for liquidity, which includes FX intervention.

${ }^{5}$ Dickey-Fuller unit root tests, of all the non-dummy variables used in the regressions, rejected the null hypotheses of non-stationarity, ensuring regressions are not spurious.
} 
market efficiency and price discovery implies abnormal returns should not last. Methodological problems in event studies include measuring abnormal returns, dating an event, outliers in small samples, controlling for heterogeneity of firms and for endogeneity from their actions influencing returns. The latter problem is less severe in short horizons of days or months, so short horizon studies such as ours are regarded as more reliable.

\begin{tabular}{|c|c|c|c|c|c|}
\hline \multicolumn{6}{|c|}{ Table 5b: Summary statistics } \\
\hline \multirow[b]{2}{*}{ Variable } & \multicolumn{5}{|c|}{$\mathbf{T}$} \\
\hline & Obs & Mean & Std. Dev. & Min & Max \\
\hline DRepo & 47 & -0.04255 & 0.425668 & -1 & 0.5 \\
\hline DCMR & 47 & -0.20774 & 1.629584 & -10.55 & 2.62 \\
\hline DCBLO & 44 & -0.17341 & 0.699282 & -2.46 & 2.54 \\
\hline D91D & 47 & -0.03002 & 0.290878 & -1.1873 & 0.633 \\
\hline D1Y & 47 & 0.019319 & 0.416113 & -0.336 & 2.711 \\
\hline D10Y & 47 & -0.00547 & 0.074504 & -0.17 & 0.177 \\
\hline LAF & 46 & 20538.9 & 50121.9 & -111990 & 145990 \\
\hline LTL & 6 & 11693.7 & 14128.2 & -10326 & 30398 \\
\hline TL & 46 & 22064.2 & 51792.3 & -111990 & 145990 \\
\hline LR1 & 46 & 0.931297 & 0.202212 & 0.149607 & 1 \\
\hline LR2 & 6 & 1.700427 & 1.914256 & 0.175927 & 4.790207 \\
\hline
\end{tabular}

\begin{tabular}{lrrrrr}
\hline \multicolumn{7}{c}{ Table 5c: Summary statistics } \\
\hline \multicolumn{7}{c}{ T \pm 5} \\
\hline Variable & Obs & Mean & Std. Dev. & Min & Max \\
\hline DRepo & 513 & -0.0039 & 0.12818 & -1 & 0.5 \\
DCMR & 513 & 0.003795 & 3.009484 & -42.76 & 45.65 \\
DCBLO & 482 & -0.0079 & 2.045091 & -20.46 & 21.38 \\
D91D & 513 & -0.00048 & 0.179307 & -1.1873 & 1.6159 \\
D1Y & 513 & -0.00356 & 0.272195 & -2.597 & 2.711 \\
D10Y & 513 & -0.00083 & 0.085499 & -0.453 & 0.549 \\
LAF & 513 & 16231.35 & 40638.7 & -120796 & 149235 \\
LTL & 513 & 252.3333 & 12134.62 & -101235 & 95760 \\
TL & 513 & 16483.68 & 41560.63 & -120796 & 149235 \\
LR1 & 429 & 1.080775 & 3.16691 & -2.04266 & 65.24887 \\
LR2 & 96 & 0.271801 & 14.17962 & -86.0444 & 90.77381 \\
\hline
\end{tabular}

In applying event studies to policy rate change there are other advantages. Unlike in VAR studies many types of interactive dummies can be used for liquidity variables. Windows are well-defined without problems in dating an event since policy dates are known. There is no problem in defining excess returns as happens in corporate or financial event studies. The short horizon reduces 
simultaneity bias. Event studies are also better than VAR estimation for this data set since many zeros in high frequency long-term liquidity data create difficulty in VAR estimation. Use of interactive dummy variables, to explore different types of interaction between rate and liquidity variables, is not possible in VAR models. One problem is short horizon outliers frequent in event windows can imply non-normality in residuals, but OLS with non-normal residuals can be used, except for forecasting, as long as $n$ exceeds 15 (Lumley and Emerson, 2002) and has been used by Qiao and Liu (2017). Also the large number of zeros, for the Repo rate, in the $\mathrm{T} \pm 5$ data set make the $\mathrm{R}^{2}$ low.

Data is collected for $\mathrm{T}$ and $\mathrm{T} \pm 5$ windows around periods of Repo rate change. The Repo rate changed 47 times in our data period. So there are few data points in the $\mathrm{T}$ period regressions. $\mathrm{T} \pm 5$ event window has 482 (minimum) observations ${ }^{6}$ and also allows us to investigate slightly longerrun market reactions. Table 5a lists the variables; Tables $5 \mathrm{~b}$ and $5 \mathrm{c}$ give the summary statistics; and Tables $6 \mathrm{a}$ and $6 \mathrm{~b}$ give pairwise correlations. DCMR, DCBLO are change in Call Money Market Rate and CBLO respectively; D91D is the change in 91-Day T-Bills rate; D1Y, D10Y are the changes in yield of G-Secs of maturities 1-Year and 10-Years; DRepo is the Repo rate change around announcement dates, LTL is long term liquidity, and TL is total liquidity.

\begin{tabular}{|c|c|c|c|c|c|c|c|c|c|c|}
\hline \multicolumn{11}{|c|}{ Table 6a: Pairwise correlation } \\
\hline \multicolumn{11}{|c|}{$\mathbf{T}$} \\
\hline & DRepo & DCMR & DCBLO & D91D & D1Y & D10Y & LAF & LTL & $\mathrm{TL}$ & \\
\hline DRepo & 1 & & & & & & & & & \\
\hline DCMR & 0.1362 & 1 & & & & & & & & \\
\hline DCBLO & -0.0093 & -0.3786 & 1 & & & & & & & \\
\hline D91D & 0.5606 & 0.092 & 0.1661 & 1 & & & & & & \\
\hline D1Y & 0.2561 & -0.061 & -0.4694 & 0.1598 & 1 & & & & & \\
\hline D10Y & 0.1743 & -0.051 & 0.076 & 0.317 & 0.4101 & 1 & & & & \\
\hline LAF & 0.1999 & 0.0906 & 0.0121 & 0.1308 & 0.0128 & 0.0411 & 1 & & & \\
\hline LTL & 0.1793 & -0.3162 & 0.0199 & 0.0688 & -0.0662 & -0.0964 & 0.774 & 1 & & \\
\hline TL & 0.2035 & 0.0829 & -0.0211 & 0.131 & 0.0376 & 0.0565 & 0.9932 & 0.8689 & & 1 \\
\hline
\end{tabular}

Notes: Tables 6a and b report the Pearson correlation matrix of variables on announcements dates. All liquidity figures are in rupees crores and all the change variables are in percentage.

\footnotetext{
${ }^{6}$ The data file was cleaned to take care of dates in which all the variables were missing (blanks) because the market was closed. Examples are dates like 07-04-02, 13-04-02, 14-04-02 etc. Cleaned data has dates in which at least one market rate or liquidity variable was non-zero. Four dates $(517-513)$ were lost because of overlaps in the intervals (Repo rate changed twice in 10 days), which occurred exactly 4 times in the period of study. The CBLO market in India was started in the year 2003. The data for this market is available only from 01/01/2004 (EPWRFITS) and thus there were a lower number of observations for this rate. There were only 6 non-zero values for LTL in the T-period window, since LTL are weekly figures. In T \pm 5 LTL had 96, TL 429, and LAF 419 non-zero values respectively. Therefore degrees of freedom for the ratios LR1 (LAF/TL) and LR2 ( LAF/LTL), where observations with zeros in the denominator drop out, were 429 and 96 respectively in $\mathrm{T} \pm 5$, but 46 and 6 in $\mathrm{T}$.
} 
Table 6b: Pairwise correlation

\begin{tabular}{|c|c|c|c|c|c|c|c|c|c|}
\hline \multicolumn{10}{|c|}{$T \pm 5$} \\
\hline & DRepo & DCMR & DCBLO & D91D & D1Y & D10Y & LAF & LTL & $\mathrm{TL}$ \\
\hline DRepo & 1 & & & & & & & & \\
\hline DCMR & 0.0242 & 1 & & & & & & & \\
\hline DCBLO & 0.0004 & 0.6671 & 1 & & & & & & \\
\hline D91D & 0.2763 & -0.0668 & -0.0139 & 1 & & & & & \\
\hline D1Y & 0.1143 & 0.0715 & 0.0426 & 0.0464 & 1 & & & & \\
\hline D10Y & 0.0286 & -0.091 & -0.0371 & 0.0614 & 0.0478 & 1 & & & \\
\hline LAF & 0.073 & 0.0204 & 0.0082 & 0.0465 & -0.0232 & 0.0031 & 1 & & \\
\hline LTL & 0.0106 & -0.0726 & -0.0674 & 0.0094 & 0.0277 & 0.0654 & -0.0725 & 1 & \\
\hline TL & 0.0745 & -0.0012 & -0.0116 & 0.0482 & -0.0146 & 0.0221 & 0.9567 & 0.2211 & 1 \\
\hline
\end{tabular}

The summary statistics show the highest volatility (standard deviations) for DCMR and DCBLO. The lowest is for D10Y. All the market rates except CBLO in period T are positively correlated with DRepo. The correlation is highest for D91D and D1Y. There are some negative correlations across rates and of rate with liquidity variables. These stylised facts and correlations will help to interpret our regression results.

Our baseline model (Model 1) is:

$$
\text { DMarketRate }_{t}=\propto+\beta \text { Depo }_{t}+u_{t}
$$

\begin{tabular}{|c|c|c|c|c|c|c|c|}
\hline \multicolumn{8}{|c|}{ Table 7: Baseline model regression results } \\
\hline \multicolumn{5}{|c|}{$\mathrm{T}$} & \multicolumn{3}{|c|}{$\mathrm{T} \pm 5$} \\
\hline \multicolumn{5}{|c|}{$\mathrm{N}=47$} & \multicolumn{3}{|c|}{$\mathrm{N}=482$} \\
\hline & & DRepo & _cons & $\mathrm{R}^{2}$ & DRepo & _cons & $\mathrm{R}^{2}$ \\
\hline \multirow[t]{2}{*}{ (1) } & DCMR & 0.522 & -0.186 & 0.019 & 0.567 & 0.00601 & 0.001 \\
\hline & & $(0.361)$ & $(0.442)$ & & $(0.585)$ & $(0.964)$ & \\
\hline \multirow[t]{2}{*}{ (2) } & DCBLO & -0.0152 & -0.174 & 0.000 & 0.00558 & -0.00789 & 0.000 \\
\hline & & $(0.952)$ & $(0.111)$ & & $(0.994)$ & $(0.933)$ & \\
\hline \multirow[t]{2}{*}{ (3) } & D91D & $0.383 * * *$ & -0.0137 & 0.314 & $0.387 * * *$ & 0.00103 & 0.076 \\
\hline & & $(4.17 \mathrm{e}-05)$ & $(0.703)$ & & $(1.91 \mathrm{e}-10)$ & $(0.893)$ & \\
\hline \multirow[t]{3}{*}{ (4) } & D1Y & $0.250^{*}$ & 0.0300 & 0.066 & $0.243 * * *$ & -0.00261 & 0.013 \\
\hline & & $(0.0823)$ & $(0.618)$ & & $(0.00960)$ & $(0.827)$ & \\
\hline & & $(0.241)$ & $(0.703)$ & & $(0.518)$ & $(0.841)$ & \\
\hline
\end{tabular}

Notes: Regression results of all market rate changes to policy rate changes:

$$
\text { DMarketRate }_{t}=\propto+\beta \text { DRepo }_{t}+u_{t}
$$

The first window is the announcement interval itself to check the instantaneous market reaction and the second window is $+(-) 5$ days around the operation event interval. All the change variables are in percentage. P-values are reported in parentheses. * ** and *** denote statistical significance at $5 \%, 1 \%$ and $0.1 \%$ levels respectively.

Table 7 shows the results of the baseline regression for all rates except 10 Year G-Secs, for which regressions are run using control variables, and are reported in tables 13 and 14. Only 91 Day and 1 Year T-Bills react significantly to a change in Repo rate for the $\mathrm{T}$ and $\mathrm{T} \pm 5$ period regressions. 
D91D has the highest coefficient. One bps (basis points) increase in DRepo increases 91 Day and 1 Year G-Secs yields by 0.383 bps and 0.25 bps respectively in $\mathrm{T}$, and $0.387 \mathrm{bps}$ and $0.24 \mathrm{bps}$ respectively in $\mathrm{T} \pm 5$. That the correlation with DRepo is highest for D91D and D1Y (stylized facts Tables $6 \mathrm{a}$ and $6 \mathrm{~b}$ ) supports these results.

To check if markets were already pricing in the expected Repo rate change, we also ran the baseline model, using the change in market rates since the last Repo rate change as the dependent variable, for the $\mathrm{T}$ and $\mathrm{T} \pm 5$ window. DCMR and DCBLO were still not significant. The coefficients of D91D and D1Y continued to be strongly significant and larger than one, with that of D91D larger, while that of D10Y was also significant but just below unity. Thus G-Secs yields are most responsive to changes in policy rates. Markets may be pricing in expected policy rates changes and then also adjusting to any surprise after the policy rate change, with the most adjustment in 91 Day G-Secs.

\begin{tabular}{|c|c|c|c|c|c|c|c|c|}
\hline & \multicolumn{4}{|c|}{$\mathrm{T}$} & \multicolumn{4}{|c|}{$\mathrm{T} \pm 5$} \\
\hline & & $\mathrm{N}=$ & & & & $\mathrm{N}=482$ & & \\
\hline & Variables & $\mathrm{RD}$ & _cons & $\mathrm{R}^{2}$ & $\mathrm{RD}$ & _cons & $\mathrm{N}$ & $\overline{\mathrm{R}^{2}}$ \\
\hline (1) & DCMR & $\begin{array}{l}0.533 \\
(0.270)\end{array}$ & $\begin{array}{l}-0.503 \\
(0.163)\end{array}$ & 0.027 & $\begin{array}{l}0.0280 \\
(0.963)\end{array}$ & $\begin{array}{l}0.00238 \\
(0.986)\end{array}$ & 513 & 0.000 \\
\hline (2) & DCBLO & $\begin{array}{c}-0.0819 \\
(0.707)\end{array}$ & $\begin{array}{l}-0.125 \\
(0.457)\end{array}$ & 0.003 & $\begin{array}{l}-0.210 \\
(0.610)\end{array}$ & $\begin{array}{l}0.00344 \\
(0.971)\end{array}$ & 482 & 0.001 \\
\hline (3) & D91D & $\begin{array}{l}0.231 * * * \\
(0.00538)\end{array}$ & $\begin{array}{l}-0.158 * * \\
(0.0101)\end{array}$ & 0.160 & $\begin{array}{l}0.0778 * * \\
(0.0311)\end{array}$ & $\begin{array}{l}-0.00442 \\
(0.585)\end{array}$ & 513 & 0.009 \\
\hline (4) & D1Y & $\begin{array}{l}0.196 \\
(0.109) \\
(0.123)\end{array}$ & $\begin{array}{l}-0.0891 \\
(0.323) \\
(0.138)\end{array}$ & 0.056 & $\begin{array}{l}0.116 * * \\
(0.0336) \\
(0.521)\end{array}$ & $\begin{array}{l}-0.00945 \\
(0.442) \\
(0.720)\end{array}$ & 513 & 0.009 \\
\hline
\end{tabular}

Notes: Regression results of all market rate changes to policy rate dummy that take the value 1 for policy rate increase.

DMarketRate $_{t}=\propto+\beta R D_{t}+u_{t}$

All the change variables are in percentage. P-values are reported in parentheses. $*$, ** and $* * *$ denote statistical significance at $5 \%, 1 \%$ and $0.1 \%$ levels.

Although CMR is the operating target for the RBI, the explanation for its insignificant coefficients may lie in the larger volatility of CMR and CBLO rates as seen in the stylised facts (tables 5a and $5 \mathrm{~b}$ and graphs 4 and 6) and also the lack of increase in LTL so that most borrowing is from the LAF window (as argued in section 2). More than policy rates, it may be the accompanying liquidity adjustments that affect these rates. We examine this by introducing liquidity variables in later regressions. 
Next, we use dummies to distinguish between periods of DRepo increase or decrease. Policy rate dummy RD is set to be 1 if DRepo increases and 0 otherwise. Table 8 gives results on direction of Repo rate changes using this dummy variable. RD is significant only for D91D. The coefficient is relatively higher for the $\mathrm{T}$ window, suggesting transmission is completed faster during tightening when the dummy variable is positive. This suggests there is asymmetry in pass through with a rise in policy rates having a stronger effect compared to a fall. After that, we introduce slope and intercept dummies in our baseline model to further test for asymmetry between policy rate increase and decrease, while controlling for the change in the Repo itself. So we estimate the following Model 2 for each market rate studied $^{7}$ :

Model 2

$$
\text { DMarketRate }_{t}=\alpha_{1}+\alpha_{2} R D_{t}+\beta_{1} \text { DRepo }_{t}+\beta_{2} \text { DRepo }_{t} * R D_{t}+u_{t}
$$

Second, to assess the additional impact of liquidity channels on transmission, we take LAFVD as 1 if LAF is in injection mode and 0 otherwise in Model 3. Thus LAFVD denotes that although liquidity is being added, short-run liquidity is in deficit mode. TLVD is 1 if Total liquidity (TL) is in absorption mode and it is 0 otherwise in Model 4. Thus TLVD denotes that long-run liquidity is being withdrawn. TL may be in surplus or already in deficit, however.

Model 3

$$
\text { DMarketRate }_{t}=\alpha_{1}+\alpha_{2} \text { LAFVD }_{t}+\beta_{1} \text { DRepo }_{t}+\beta_{2} \text { DRepo }_{t} * \operatorname{LAFVD}_{t}+u_{t}
$$

Model 4

$$
\text { DMarketRate }_{t}=\alpha_{1}+\alpha_{2} \text { TLVD }_{t}+\beta_{1} \text { DRepo }_{t}+\beta_{2} \text { DRepo }_{t} * T L V D_{t}+u_{t}
$$

None of the coefficients are significant for CMR. Only significant results are reported in the tables. Others are available on request.

Table 9a shows the results for CBLO market and 1 Year G-Secs. Only T window coefficients are significant, supporting immediate impact of DRepo on CBLO rates. The DRepo coefficient becomes significant, when LAFVD is positive or short-run liquidity is injected. The injection itself tends to reduce the CBLO rates. The interaction of DRepo with the TL Dummy is also significant. CBLO falls when LAF liquidity is injected but rises when total liquidity is drained in absorption mode. Thus changes in liquidity matter. The quantum channel makes the rate channel functional. The Repo Dummy is insignificant, revealing that CBLO rates respond to Repo rate

\footnotetext{
${ }^{7}$ As a robustness exercise, the models below were regressed through the origin and the results obtained were similar to the OLS regressions.
} 
increase or decrease in a similar manner, when DRepo is included. Repo rate change dominates the direction effect of a Repo rate change. Thus complementary changes in short-run liquidity are essential for change in the Repo rate to affect the CBLO rate.

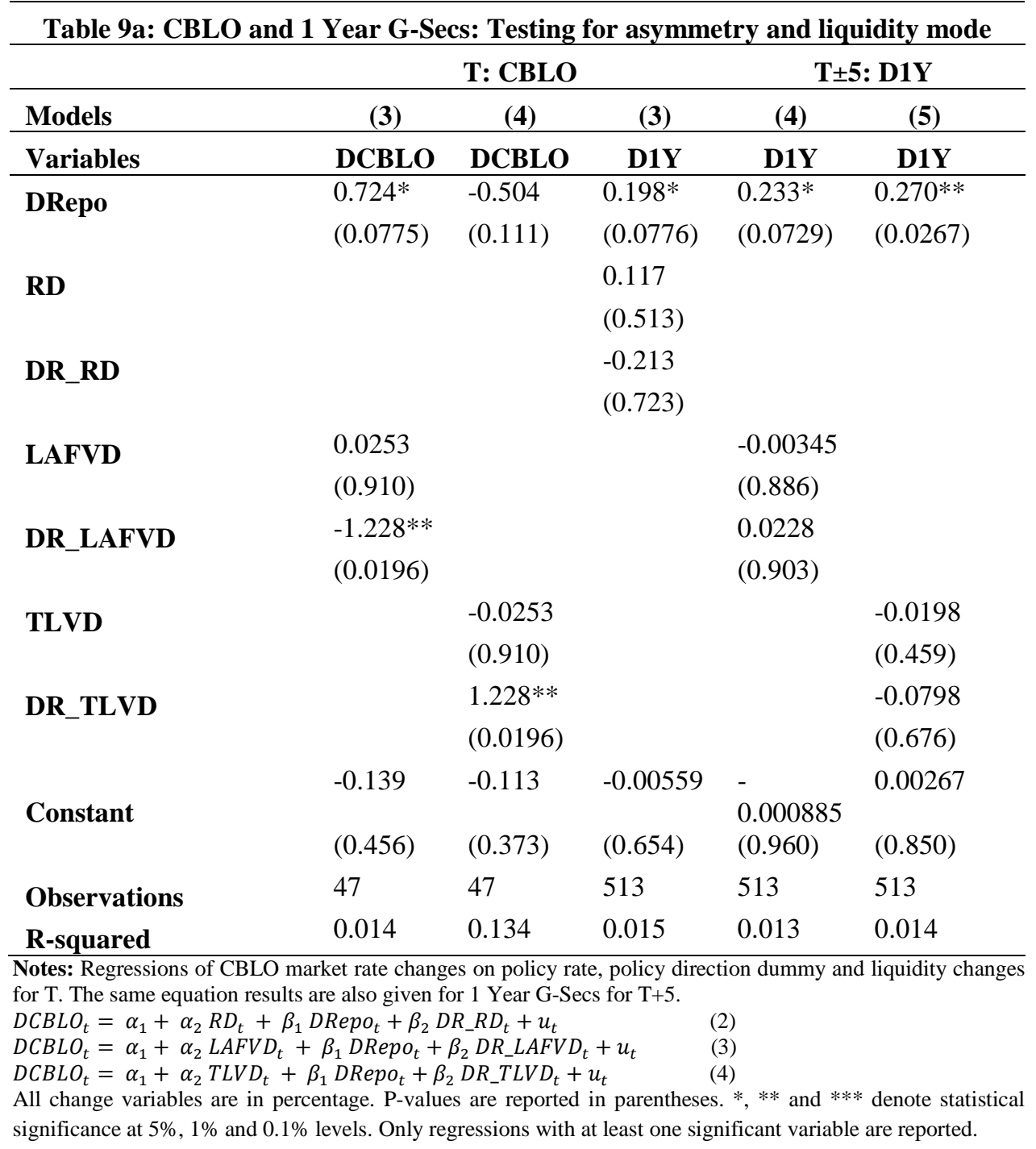

Liquidity variables are not significant for either event window for 1 Year G-Secs. DRepo coefficients are significant only in the $\mathrm{T} \pm 5$ window. They are largest in the presence of the TLVD, suggesting TL matters for longer maturity G-Secs. There is no asymmetry.

Table 9b displays the results for 91 Day Treasury Bills market. The DRepo coefficients remain significant and rise in size in the presence of liquidity variables, although the latter are not themselves significant. The dominant and significant interaction term for DRepo and RD in $\mathrm{T} \pm 5$ supports asymmetry - transmission to G-Secs rates is faster during tightening when the Repo rate is rising, than when it is falling. The reason may be large government borrowing. 
Table 9b: 91 Day T-Bills: Testing for asymmetric and liquidity mode

\begin{tabular}{|c|c|c|c|c|c|c|}
\hline & \multicolumn{3}{|c|}{$\mathbf{T}$} & \multicolumn{3}{|c|}{$\mathbf{T} \pm \mathbf{5}$} \\
\hline Models & (2) & (3) & (4) & (2) & (3) & (4) \\
\hline Variables & D91D & D91D & D91D & D91D & D91D & D91D \\
\hline \multirow{2}{*}{ DRepo } & $0.553 * * *$ & $0.460 * * *$ & $0.305 * * *$ & $0.414 * * *$ & $0.467 * * *$ & $0.306 * * *$ \\
\hline & $(0.00393)$ & $(0.00228)$ & $(0.00793)$ & $(9.98 \mathrm{e}-09)$ & $(2.33 \mathrm{e}-08)$ & $(8.37 \mathrm{e}-05)$ \\
\hline \multirow{2}{*}{ RD } & $-0.340^{*}$ & & & $-0.251 * *$ & & \\
\hline & $(0.0736)$ & & & $(0.0270)$ & & \\
\hline \multirow[t]{2}{*}{ DR_RD } & 0.559 & & & $0.699 *$ & & \\
\hline & $(0.317)$ & & & $(0.0670)$ & & \\
\hline \multirow[t]{2}{*}{ LAFVD } & & 0.0670 & & & 0.0210 & \\
\hline & & $(0.401)$ & & & $(0.170)$ & \\
\hline \multirow{2}{*}{ DR_LAFVD } & & -0.155 & & & -0.184 & \\
\hline & & $(0.392)$ & & & $(0.124)$ & \\
\hline \multirow{2}{*}{ TLVD } & & & -0.0670 & & & -0.0209 \\
\hline & & & $(0.401)$ & & & $(0.220)$ \\
\hline \multirow{2}{*}{ DR_TLVD } & & & 0.155 & & & 0.185 \\
\hline & & & $(0.392)$ & & & $(0.128)$ \\
\hline \multirow[t]{2}{*}{ Constant } & 0.0922 & -0.0522 & 0.0148 & 0.00366 & -0.00925 & 0.00760 \\
\hline & $(0.349)$ & $(0.431)$ & $(0.737)$ & $(0.644)$ & $(0.409)$ & $(0.397)$ \\
\hline Observations & 47 & 47 & 47 & 513 & 513 & 513 \\
\hline R-squared & 0.364 & 0.343 & 0.343 & 0.086 & 0.084 & 0.084 \\
\hline
\end{tabular}

Notes: $D 91 D_{t}=\alpha_{1}+\alpha_{2} R D_{t}+\beta_{1}$ Repo $_{t}+\beta_{2} D R R_{-} R D_{t}+u_{t}$

$D 91 D_{t}=\alpha_{1}+\alpha_{2} L A F V D_{t}+\beta_{1} D$ Repo $_{t}+\beta_{2} D R_{-} L A F V D_{t}+u_{t}$

$D 91 D_{t}=\alpha_{1}+\alpha_{2} T_{L V} D_{t}+\beta_{1} D_{R e p o}+\beta_{2} D R_{-} T L V D_{t}+u_{t}$

Results of estimating equations of models (2), (3) and (4) above are given. All change variables are in percentage. P-values are reported in parentheses. *,** and $* * *$ denote statistical significance at $5 \%, 1 \%$ and $0.1 \%$ levels. Only regressions with at least one significant variable are reported.

\begin{tabular}{|c|c|c|c|c|}
\hline \multicolumn{5}{|c|}{ Table 10a: Combinations of LAF and Repo rate changes } \\
\hline & \multicolumn{2}{|r|}{ DRepo $>0$} & \multicolumn{2}{|c|}{ DRepo $<0$} \\
\hline & Coefficients & Interpretation & Coefficients & Interpretations \\
\hline $\mathbf{L A F}>0$ & $\begin{array}{l}\text { Constant + RD + } \\
\text { LAFVD + } \\
(\text { RD*LAFVD) }\end{array}$ & $\begin{array}{l}\text { Increase in Repo rate during LAF } \\
\text { injection }\end{array}$ & Constant + LAFVD & $\begin{array}{l}\text { Decrease in Repo rate during } \\
\text { LAF injection }\end{array}$ \\
\hline $\mathbf{L A F}<0$ & Constant + RD & $\begin{array}{l}\text { Increase in Repo rate during LAF } \\
\text { absorption }\end{array}$ & Constant & $\begin{array}{l}\text { Decrease in Repo rate during } \\
\text { LAF absorption }\end{array}$ \\
\hline
\end{tabular}

Notes: The above table displays the different types of open market operations-Panel a for LAF and Panel b for Total liquidity.

\begin{tabular}{|c|c|c|c|c|}
\hline \multicolumn{5}{|c|}{ Table 10b: Combinations of Total liquidity and Repo Rate changes } \\
\hline & \multicolumn{2}{|c|}{ DRepo $>0$} & \multicolumn{2}{|c|}{ DRepo $<0$} \\
\hline & Coefficients & Interpretation & Coefficients & Interpretations \\
\hline $\mathbf{T L}<0$ & $\begin{array}{l}\text { Constant + RD + TLVD } \\
+(\text { RD*TLVD })\end{array}$ & $\begin{array}{l}\text { Increase in Repo rate during TL } \\
\text { absorption }\end{array}$ & Constant + TLVD & $\begin{array}{l}\text { Decrease in Repo rate during } \\
\text { TL absorption }\end{array}$ \\
\hline TL $>0$ & Constant $+\mathrm{RD}$ & $\begin{array}{l}\text { Increase in Repo rate during TL } \\
\text { injection }\end{array}$ & Constant & $\begin{array}{l}\text { Decrease in Repo rate during } \\
\text { TL injection }\end{array}$ \\
\hline
\end{tabular}


Although the volume and volume interaction dummies are rarely significant in models 3 and 4, the controls for the quantum channels increase the size of the DRepo coefficients, compared to the baseline model, suggesting the quantum channel increases the impact of a change in the Repo rate.

Next we investigate results for settings when liquidity and repo changes work in sync with each other, that is, when liquidity changes are in the same direction as Repo rate changes. For example, for periods when the Repo rate is rising so RD equals one, we take the periods when the LAF was in injection mode and the TL in absorption mode as indicated by the dummy variables (tables 10a and $10 \mathrm{~b}$ ). The relevant coefficients under four different combinations of Repo, LAF and TL change are listed in Table 11. The models used are:

Model 5

$$
\text { DMarketRate }_{t}=\alpha+\beta_{1} R D_{t}+\beta_{2} L A F V D_{t}+\beta_{3} R D_{t} * L A F V D_{t}
$$

Model 6

$$
\text { DMarketRate }_{t}=\alpha+\beta_{1} R D_{t}+\beta_{2} T L V D_{t}+\beta_{3} R D_{t} * T L V D_{t}
$$

\begin{tabular}{llcccc}
\hline \multicolumn{6}{c}{ Table 11: 91 Day T-Bills and 1 Year G-Secs: Testing for synchronous Repo and liquidity } \\
changes
\end{tabular}

Notes: Results are given from estimating equations below of models (5) and (6) for effect on 91 Day T-Bills in two different scenarios. First, Repo rate is increasing and LAF is in injection mode. Second, Repo rate is increasing and Total liquidity is in absorption mode. The same estimations are also given for 1 Year $\mathrm{G}-\mathrm{Secs}$ in $\mathrm{T} \pm 5$.

$D 91 D_{t}=\alpha+\beta_{1} R D_{t}+\beta_{2} L A F V D_{t}+\beta_{3} R D_{-} L A F V D_{t}$

$D 91 D_{t}=\alpha+\beta_{1} R D_{t}+\beta_{2} T L V D_{t}+\beta_{3} R D \bar{T} L V D_{t}$

$\mathrm{P}$-values are reported in parentheses. $*, * *$ and $* * *$ denote statistical significance at $5 \%, 1 \%$ and $0.1 \%$ levels. Only regressions with at least one significant variable are reported. 
The relevant baseline models to compare with these models are those with only the repo dummy (RD) given in Table 8. The RD coefficient continues to be insignificant for CMR and CBLO, with no evidence in support of synchronous liquidity. None of the liquidity variables are significant but the size of the significant RD coefficient rises for D91D (both $\mathrm{T}$ and $\mathrm{T} \pm 5$ ) and for 1 Year G-Secs (only T) in regressions where the TL dummy is introduced, suggesting TL is important for transmission in G-Secs markets (Table 11). This again suggests that quantity variables intensify the pass through of Repo Rate changes.

To assess the relative effect of short- versus long-term liquidity, we will now insert liquidity ratios one by one in the baseline model. We define LR1 $=\mathrm{LAF} / \mathrm{TL}$ and LR2 $=$ LAF/LTL as the two liquidity ratios. The new models are:

Model 7

$$
\text { DMarketRate }_{t}=\propto+\beta \text { DRepo }_{t}+\gamma L R 1_{t}+u_{t}
$$

Model 8

$$
\text { DMarketRate }_{t}=\propto+\beta \text { DRepo }_{t}+\delta L R 2_{t}+u_{t}
$$

\begin{tabular}{|c|c|c|c|c|}
\hline & $\mathbf{T}$ & & $\mathrm{T} \pm 5$ & \\
\hline Models & (7) & (7) & (7) & (8) \\
\hline Variables & DCBLO & D91D & D91D & D91D \\
\hline \multirow[t]{2}{*}{ DRepo } & 0.333 & $0.384 * * *$ & $0.387 * * *$ & -0.122 \\
\hline & $(0.142)$ & $(0.000138)$ & $(3.48 \mathrm{e}-08)$ & $(0.508)$ \\
\hline \multirow[t]{2}{*}{ LR1 } & $2.009 * * *$ & -0.0136 & $-0.00506^{*}$ & \\
\hline & $(0.000282)$ & $(0.942)$ & $(0.0779)$ & \\
\hline \multirow[t]{2}{*}{ LR2 } & & & & 0.000365 \\
\hline & & & & $(0.690)$ \\
\hline \multirow[t]{2}{*}{ Constant } & $-2.103^{* * *}$ & -0.00136 & 0.00790 & $-\overline{0.0365 * * *}$ \\
\hline & $(9.43 e-05)$ & (0.994) & $(0.410)$ & $(0.00561)$ \\
\hline Observations & 43 & 46 & 429 & 96 \\
\hline R-squared & 0.293 & 0.291 & 0.075 & 0.006 \\
\hline
\end{tabular}

Tables $12 \mathrm{a}$ and $12 \mathrm{~b}$ give results for those of the above models where liquidity ratios are significant. LR1 has a positive impact on CBLO in T (Table $12 \mathrm{a})^{5}$ and a negative impact on GSecs yields. This is consistent with the negative interaction coefficient for LAFVD in Table 9a Model 3, since the LR1 ratio, which is always positive, is higher when LAF is in absorption mode 
to compensate for higher total liquidity. Its negative coefficients for G-Secs yields suggest that higher total and long-run liquidity reduces G-Secs yields. DRepo is significant for some rates, which further supports the dominant role of the interest rate channel.

\begin{tabular}{lcccc}
\hline \multicolumn{5}{c}{ Table 12b: 1 and 10-Year G-Secs: Testing for the effect of short } \\
versus long-term liquidity & \multicolumn{2}{c}{ T $\mathbf{5}$} & $\mathbf{T}$ \\
\hline Models & $\mathbf{T}$ & $\mathbf{( 7 )}$ & $\mathbf{( 8 )}$ & $\mathbf{( 7 )}$ \\
\hline Variables & $\mathbf{D 1}$ & $\mathbf{D 1 Y}$ & $\mathbf{D 1 Y}$ & $\mathbf{D 1 0 Y}$ \\
\hline DRepo & 0.190 & $0.230^{* *}$ & $1.420 * * *$ & $0.0474 *$ \\
& $(0.134)$ & $(0.0333)$ & $(0.00216)$ & $(0.0636)$ \\
LR1 & $-1.179 * * *$ & 0.000473 & & $-0.109 * *$ \\
& $(2.45 \mathrm{e}-05)$ & $(0.916)$ & & $(0.0340)$ \\
LR2 & & & -0.000412 & \\
& & & $(0.854)$ & \\
Constant & $1.129 * * *$ & -0.00536 & 0.0422 & $0.0946 *$ \\
& $(2.22 \mathrm{e}-05)$ & $(0.721)$ & $(0.184)$ & $(0.0530)$ \\
Observations & 46 & 429 & 96 & 46 \\
R-squared & 0.376 & 0.011 & 0.097 & 0.175 \\
\hline
\end{tabular}

Tables 13 and 14 present the results of all the models for D10Y regressed on DRepo, including control variables that affect long-run yields. These include variables affecting future risks and returns and demand and supply of G-Secs. Expected growth (monthly IIP growth rates used as a proxy) and expected inflation (one year ahead monthly CPI inflation used as a proxy) capture future risks and returns. Quarterly fiscal deficit to GDP ratio captures supply of G-Secs. The daily US fed rate, weekly OMO to narrow money ratio and banks' yearly excess SLR ratio capture demand for G-Secs by foreign investors, RBI and banks respectively. The FD and SLR variables are not satisfactory since approximations from lower frequencies are used with daily data, but still there are some interesting results.

Neither DRepo nor RD alone is significant even with controls. Despite the inclusion of control variables the results are similar to those for shorter-run G-Secs yields. The DRepo is significant only in the $\mathrm{T}$ period regression with LR1, while LR1 itself has a negative coefficient (even without controls in Table 12b) and expected inflation is positive. LAFVD has a positive and TLVD a negative coefficient. As for the other G-Secs, a surplus liquidity environment softens yields, and liquidity variables increase transmission of Repo changes. A positive interaction coefficient between DRepo and the tightening dummy in both $\mathrm{T}$ and $\mathrm{T} \pm 5$ regressions provides some support for asymmetry or faster transmission during tightening. For the $\mathrm{T} \pm 5$ window changes in the US federal funds rate has a low positive significant coefficient, while a negative 
coefficient averaging unity for the OMO ratio also suggests that rise in long-run liquidity softens 10 year G-Secs yields.

\begin{tabular}{|c|c|c|c|c|}
\hline \multicolumn{5}{|c|}{ Table 13: 10 year G-Secs $(T)$ with control variables } \\
\hline \multicolumn{5}{|c|}{$\mathbf{T}$} \\
\hline Models & (2) & (5) & (6) & (7) \\
\hline Variables & D10Y & D10Y & D10Y & D10Y \\
\hline \multirow[t]{2}{*}{ DRepo } & -0.0678 & & & $0.0463^{*}$ \\
\hline & $(0.333)$ & & & $(0.0936)$ \\
\hline \multirow[t]{2}{*}{$\mathrm{RD}$} & -0.0594 & 0.0581 & 0.00633 & \\
\hline & $(0.340)$ & $(0.161)$ & $(0.833)$ & \\
\hline \multirow[t]{2}{*}{ DR_RD } & $0.482 * *$ & & & \\
\hline & $(0.0213)$ & & & \\
\hline \multirow[t]{2}{*}{ LAFVD } & & $0.0686^{*}$ & & \\
\hline & & $(0.0683)$ & & \\
\hline \multirow[t]{2}{*}{ RD_LAFVD } & & -0.0518 & & \\
\hline & & $(0.318)$ & & \\
\hline \multicolumn{5}{|l|}{ DR_LAFVD } \\
\hline \multirow[t]{2}{*}{ TLVD } & & & $-0.0686^{*}$ & \\
\hline & & & $(0.0683)$ & \\
\hline \multirow[t]{2}{*}{ DR_TLVD } & & & 0.0518 & \\
\hline & & & $(0.318)$ & \\
\hline \multirow[t]{2}{*}{ LR1 } & & & & $-0.162 * * *$ \\
\hline & & & & $(0.00655)$ \\
\hline \multicolumn{5}{|l|}{ LR2 } \\
\hline \multirow[t]{2}{*}{ DFF } & 0.221 & 0.469 & 0.469 & 0.540 \\
\hline & $(0.618)$ & $(0.245)$ & $(0.245)$ & $(0.214)$ \\
\hline \multirow[t]{2}{*}{ SLR_EX } & -0.115 & -0.496 & -0.496 & -0.220 \\
\hline & $(0.823)$ & $(0.350)$ & $(0.350)$ & $(0.650)$ \\
\hline \multirow[t]{2}{*}{ FDRatio } & -0.155 & -0.164 & -0.164 & -0.0780 \\
\hline & $(0.536)$ & $(0.528)$ & $(0.528)$ & $(0.734)$ \\
\hline \multirow[t]{2}{*}{ CPIIR_1Y } & 0.00107 & 0.0101 & 0.0101 & $0.0218^{*}$ \\
\hline & $(0.931)$ & $(0.398)$ & $(0.398)$ & $(0.0600)$ \\
\hline \multirow[t]{2}{*}{ IIPGR_1Y } & -0.00368 & -0.00149 & -0.00149 & -0.00186 \\
\hline & $(0.229)$ & $(0.615)$ & $(0.615)$ & $(0.497)$ \\
\hline \multirow[t]{2}{*}{ OMOM1 } & 0.430 & 0.0119 & 0.0119 & -0.571 \\
\hline & $(0.773)$ & (0.994) & (0.994) & $(0.687)$ \\
\hline \multirow[t]{2}{*}{ Constant } & -0.0442 & -0.0489 & 0.0197 & $0.144 * *$ \\
\hline & $(0.267)$ & $(0.145)$ & $(0.567)$ & $(0.0144)$ \\
\hline Observations & 46 & 46 & 46 & 45 \\
\hline R-squared & 0.237 & 0.199 & 0.199 & 0.286 \\
\hline
\end{tabular}

Notes: Significant results from regressions of D10Y on DRepo, RD and models (2) to (8) for T including control variables. Table 14 below is for the $\mathrm{T} \pm 5$ window.

P-values are reported in parentheses. *, ** and *** denote statistical significance at $5 \%, 1 \%$ and $0.1 \%$ levels. 
Table 14: 10 year $G-S e c s(T \pm 5)$ with control variables

\section{$\mathbf{T} \pm \mathbf{5}$}

\begin{tabular}{|c|c|c|c|c|c|c|c|c|c|}
\hline Models & Baseline & $\mathrm{RD}$ & (2) & (3) & (4) & (5) & (6) & (7) & (8) \\
\hline VARIABLES & D10Y & D10Y & D10Y & D10Y & D10Y & D10Y & D10Y & D10Y & D10Y \\
\hline \multirow[t]{2}{*}{ DRepo } & 0.0242 & & 0.00965 & 0.00156 & 0.0138 & & & 0.0439 & -0.0302 \\
\hline & (0.419) & & (0.789) & $(0.970)$ & $(0.722)$ & & & $(0.206)$ & $(0.848)$ \\
\hline \multirow[t]{2}{*}{$\mathrm{RD}$} & & 0.00978 & -0.0850 & & & -0.00647 & 0.0143 & & \\
\hline & & $(0.574)$ & $(0.138)$ & & & $(0.845)$ & $(0.484)$ & & \\
\hline \multirow[t]{2}{*}{ DR_RD } & & & $0.318^{*}$ & & & & & & \\
\hline & & & $(0.0989)$ & & & & & & \\
\hline \multirow[t]{2}{*}{ LAFVD } & & & & 0.00459 & & 0.00364 & & & \\
\hline & & & & $(0.558)$ & & $(0.649)$ & & & \\
\hline \multirow[t]{2}{*}{ RD_LAFVD } & & & & & & 0.0213 & & & \\
\hline & & & & & & $(0.587)$ & & & \\
\hline \multirow[t]{2}{*}{ DR_LAFVD } & & & & 0.0445 & & & & & \\
\hline & & & & $(0.463)$ & & & & & \\
\hline \multirow[t]{2}{*}{ TLVD } & & & & & -0.00847 & & -0.00824 & & \\
\hline & & & & & $(0.340)$ & & $(0.364)$ & & \\
\hline \multirow[t]{2}{*}{ DR_TLVD } & & & & & 0.0209 & & -0.0168 & & \\
\hline & & & & & $(0.734)$ & & $(0.669)$ & & \\
\hline \multirow[t]{2}{*}{ LR1 } & & & & & & & & 0.000918 & \\
\hline & & & & & & & & $(0.526)$ & \\
\hline \multirow[t]{2}{*}{ LR2 } & & & & & & & & & 0.000704 \\
\hline & & & & & & & & & $(0.366)$ \\
\hline \multirow[t]{2}{*}{ DFF } & $0.149^{*}$ & $0.143^{*}$ & $0.145^{*}$ & $0.147^{*}$ & $0.150^{*}$ & $0.144^{*}$ & $0.145^{*}$ & $0.181 * *$ & 0.0871 \\
\hline & $(0.0550)$ & $(0.0645)$ & $(0.0613)$ & $(0.0587)$ & $(0.0526)$ & $(0.0628)$ & $(0.0618)$ & $(0.0469)$ & $(0.738)$ \\
\hline \multirow[t]{2}{*}{ SLR_EX } & -0.0290 & -0.0317 & -0.0110 & -0.00900 & -0.0164 & -0.0211 & -0.00939 & -0.00756 & -0.626 \\
\hline & $(0.863)$ & $(0.851)$ & $(0.948)$ & $(0.958)$ & $(0.923)$ & $(0.901)$ & $(0.956)$ & $(0.970)$ & $(0.188)$ \\
\hline \multirow[t]{2}{*}{ FDRatio } & 0.00608 & 0.00436 & -0.00249 & 0.00655 & -0.00115 & 0.00284 & -0.00286 & 0.0164 & -0.230 \\
\hline & $(0.942)$ & $(0.958)$ & $(0.976)$ & $(0.938)$ & $(0.989)$ & $(0.973)$ & $(0.973)$ & $(0.867)$ & $(0.341)$ \\
\hline \multirow[t]{2}{*}{ CPIIR_1Y } & 0.00579 & 0.00573 & 0.00531 & 0.00582 & 0.00620 & 0.00583 & 0.00601 & 0.00540 & -0.00946 \\
\hline & $(0.180)$ & $(0.185)$ & $(0.219)$ & $(0.179)$ & $(0.153)$ & $(0.179)$ & $(0.166)$ & $(0.303)$ & $(0.453)$ \\
\hline \multirow[t]{2}{*}{ IIPGR_1Y } & 0.000600 & 0.000558 & 0.000473 & 0.000612 & 0.000621 & 0.000587 & 0.000577 & 0.000659 & 0.000767 \\
\hline & $(0.553)$ & $(0.580)$ & $(0.641)$ & $(0.545)$ & $(0.540)$ & $(0.562)$ & $(0.568)$ & $(0.582)$ & $(0.797)$ \\
\hline \multirow[t]{2}{*}{ OMOM1 } & $-0.968 *$ & $-0.962^{*}$ & $-0.963 *$ & $-1.006^{*}$ & $-1.046 * *$ & $-0.990^{*}$ & $-1.040 * *$ & $-1.104 *$ & $-2.707 *$ \\
\hline & $(0.0617)$ & $(0.0634)$ & $(0.0628)$ & $(0.0536)$ & $(0.0463)$ & $(0.0577)$ & $(0.0476)$ & $(0.0770)$ & $(0.0505)$ \\
\hline \multirow[t]{2}{*}{ Constant } & -0.00305 & -0.00349 & -0.00344 & -0.00636 & 0.000820 & -0.00567 & -0.00161 & -0.00611 & 0.0200 \\
\hline & $(0.670)$ & $(0.630)$ & $(0.635)$ & $(0.455)$ & $(0.913)$ & $(0.505)$ & $(0.832)$ & $(0.476)$ & $(0.351)$ \\
\hline Observations & 502 & 502 & 502 & 502 & 502 & 502 & 502 & 419 & 94 \\
\hline R-squared & 0.021 & 0.020 & 0.027 & 0.023 & 0.023 & 0.022 & 0.023 & 0.028 & 0.119 \\
\hline
\end{tabular}

To summarize the results for monetary transmission and the interaction between rate and liquidity channels: Short run G-Secs yields are most responsive to changes in policy rates-91 Day G-Secs show the most adjustment. Asymmetry or faster and more adjustment during tightening is found only for G-Secs rates. CBLO responds to the direction of change in DRepo when liquidity 
changes are aligned, that is liquidity falls in periods of tightening and rises during accommodation. Keeping liquidity in deficit irrespective of the cycle does not help transmission.

The DRepo coefficients in G-Secs regressions are largest in the presence of the TLVD, suggesting total liquidity matters for longer maturity G-Secs. Liquidity variables increase the size of the GSecs DRepo coefficients, compared to the baseline model, suggesting aligned liquidity increases the impact of a change in the Repo rate. The policy implication is liquidity and repo changes should work in sync with each other.

\section{Conclusion}

This paper uses OLS regressions of event windows around change in Repo rates to explore the relative performance and interaction of rate and liquidity channels in Indian monetary transmission. This is important since the RBI had moved to keeping long-run liquidity in deficit regardless of the easing or tightening style. The results show that the interest rate channel, with Repo rate as the policy rate, is the most effective medium to influence market rates. Over the years, RBI has been quite successful in controlling market rates through adjustments in Repo and Reverse Repo rates. After 2012, market rates have operated within the corridor defined by the Repo and Reverse Repo rates.

However, the interaction between rate and liquidity channels is important for monetary transmission. Short run G-Secs yields are most responsive to changes in policy rates. Since it increases the size of response to Repo change total liquidity matters for longer maturity G-Secs. CBLO rates respond to the direction of change in DRepo when liquidity changes are aligned, that is liquidity falls in periods of tightening and rises during accommodation. Keeping long term liquidity tight so that the LAF is in deficit irrespective of the cycle does not help transmission. Therefore aligned liquidity would increase the impact of a change in the Repo rate. Asymmetry or faster and more adjustment during tightening is found only for G-Secs rates.

What are the implications for current policy positions? Our results do not support the RBI practice of keeping the CMR as the operating target. Since coefficients for CMR continue to be insignificant, there is no evidence for the RBI (2011) view that pass through is most rapid for the CMR since it reflects demand by liquidity constrained banks. Table 4 also shows that during the easing phase V (May 2012 to Sept. 2013) when liquidity was in deficit, market rates did not follow the direction of Repo rate change. Liquidity provision matters more in thin markets. 
Therefore the 2016 move away from maintaining liquidity in deficit, even while narrowing the LAF corridor, is in the right direction.

CBLO rates or 91 Day T-bills could be the operating target. Liquidity provision should be aligned to the cycle. Since too many exogenous shocks affect liquidity in EMs the share of durable liquidity can fall too low, so keeping liquidity in surplus may work better.

With LTL in deficit the call money market share of the money market has fallen to only 10 per cent, with most LAF borrowing being done from the RBI as predicted by the analytical framework. For a LAF corridor to work well, shocks to LTL have to be predicted and responded to as in AEs. But EMs are asymmetric in that there are more such shocks due to demand for cash, lumping of government spending, and volatile foreign capital flows. Therefore, in EMs it is better to maintain LTL in surplus with the LAF in absorption mode especially when policy is loosening. In a narrow LAF corridor- the Indian range in 0.25- even if the CMR sometimes touches the bottom, the Repo rate will remain the effective policy signal.

That Indian CMR volatility has decreased in recent periods (Graph 4), however, suggests markets are deepening and the policy response to liquidity shocks is improving. But intraday CMR volatility remains large because while most of the borrowing is completed when markets open, some banks try to dispose last hour post-netting liquidity in this market so the CMR falls. Moreover, while there are plans to start a remunerated standing deposit facility with a low rate, it has not yet materialized. Indian banks depend more on deposits for liquidity than on the interbank market. They do not lend-long term based on interbank borrowing, since they are uncertain of future rates.

Moreover, since the call money market is uncollateralized access has been restricted only to banks and primary dealers to ensure market integrity. It, therefore, does not capture system-wide stresses in liquidity. CBLO has the disadvantage of being a collateralized market. Therefore it also does not reflect all demand for liquidity. 91 Day T-bills give asset side transmission, which is affected by systemic liquidity, without being infected by the other macroeconomic variables that impact longer-term G-Secs. Liquidity and repo changes should work in sync with each other, even for pass through to G-Sec rates.

The US federal funds rate affects 10 year G-Sec yields, but OMOs have the highest coefficient suggesting that domestic liquidity can, to some extent, counter the effect of external rate changes. 
Keeping liquidity in deficit only raises the cost of government borrowing without improving transmission, particularly in the easing phase. Since the corporate bond market is yet to mature changes in the risk-free rate do not affect a large share of market borrowings. Uncertainty and credit risk raises spreads. Market feedback has also consistently brought out the importance of liquidity for interest rate pass through (Das 2018).

Possible extensions include examining the role of Repo markets and outcomes in windows longer than $\mathrm{T}$ and $\mathrm{T} \pm 5$. The impact of liquidity on $\mathrm{G}$-Sec rates can be explored using the entire data set. Transmission to bank lending rates is of major interest and needs rigorous analysis. It requires alternative approaches, however, as it cannot be captured in $\mathrm{T} \pm 5$ day windows. The impact of liquidity on G-Secs rates explored using the entire data set in Goyal (2019) supports the importance of OMOs.

\section{References}

Aleem, A. 2010. 'Transmission mechanism of monetary policy in India.' Journal of Asian Economics, 21 (2): 186-197.

Bhoi, B.K., A.K. Mitra, J.B. Singh and G. Sivaramakrishnan. 2017. 'Effectiveness of alternative channels of monetary policy transmission: some evidence for India.' Macroeconomics and Finance in Emerging Market Economies, 10 (1): 19-38.

Borio, Claudio E.V. 1997. 'The implementation of monetary policy in industrial countries: A survey,' Bank for International Settlements, Economic Paper no. 47.

Carpenter, S. and S. Demiralp. 2006. 'The liquidity effect in the federal funds market: Evidence from daily open market operations.' Journal of Money, Credit and Banking, 38(4): 901-920.

Das, S. 2018. 'Bond market looks for more OMOs to check yield rise.' Economic Times, June 21: 10.11 AM IST.

Das, S. 2016. 'Reserve Bank of India's stance on liquidity irks markets.' Economic Times, February 02: 05.55 PM IST.

Demiralp, S. and D. Farley. 2005. 'Declining required reserves, funds rate volatility, and open market operations.' Journal of Banking and Finance, 29 (5): 1131-1152.

Guthrie, G., and J. Wright. 2000. 'Open mouth operations.' Journal of Monetary Economics, Elsevier, 46 (2): 489-516, October.

Freixas, X, A. Martin and D. Skeie. 2011. 'Bank liquidity, interbank markets, and monetary policy.' The Review of Financial Studies, 24 (8): 2656-2692.

Goyal, A. 2019. 'Government Securities Market: Price Discovery, Monetary Management and Government Borrowing,' Economic and Political Weekly, Special issue on Money, Banking and Finance, 54(13): 44-58. 30 March. 
Kanagasabapathy, K., R. A. Bhangaonkar and S. R. Pandey. 2014. 'Monetary policy transmission in India: Interplay of rate and quantum channels.' In Goyal, A. (ed.) A Concise Handbook of the Indian Economy in the 21st Century, Chapter 6. Delhi: OUP.

Khotari, S. P. and J. B. Warner. 2016. 'Econometrics of event studies.' Chapter 1 in B. Espen Eckbo (ed.), Handbook of Corporate Finance: Empirical Corporate Finance, Volume A (Handbooks in Finance Series). Elsevier: North-Holland.

Khundrakpam, J. K. and R. Jain. 2012. 'Monetary policy transmission in India: A peep inside the black box.' RBI working paper series no. 11 . https://www.rbi.org.in/scripts/PublicationsView.aspx?id=14326.

Lumley T, Emerson S. 2002. 'The importance of the normality assumption in large public health data sets.' Annual Review of Public Health. 23:151-69.

Mishra, A. and V. Mishra. 2012. 'Inflation targeting in India: A comparison with the multiple indicator approach.' Journal of Asian Economics, 23: 86-98.

Qiao, Z. and Y. Liu. 2017. 'Open market operation effectiveness in China.' Emerging Markets Finance and Trade, 53(8):1706-1719.

RBI (Reserve Bank of India). 2011. 'Report of the working group on operating procedures of monetary policy.' $15^{\text {th }}$ March. Accessed September 2017.

https://www.rbi.org.in/scripts/PublicationReportDetails.aspx?ID=631

RBI (Reserve Bank of India). 2014. 'Report of the expert committee to revise and strengthen the monetary policy framework.' (January). Accessed September 2017.

https://rbidocs.rbi.org.in/rdocs/PublicationReport/Pdfs/ECOMRF210114_F.pdf

RBI (Reserve Bank of India). 2016. 'Reserve Bank of India annual report 2015-16.' Accessed September 2017. https://www.rbi.org.in/Scripts/AnnualReportPublications.aspx?year=2016

RBI (Reserve Bank of India). 2017. 'Handbook of Statistics on Indian Economy'. Accessed September 2017. http://www.rbi.org.in

Walsh, C. 1998. Monetary theory and policy. MIT Press: Cambridge MA 